\title{
Impactos do comportamento inovativo das grandes empresas nacionais e estrangeiras da indústria de transformação brasileira no desenvolvimento do Sistema Nacional de Inovação *
}

\author{
Adriano José Pereira \\ Professor - Universidade Federal de Santa Maria (UFSM) \\ Endereço: Av. Roraima, 1000 - Cidade Universitária, Camobi - Santa Maria/RS - Brasil \\ CEP: $97105-900$ - E-mail: adrianoeconomia@ufsm.br
}

Ricardo Dathein

Professor - Universidade Federal do Rio Grande do Sul (UFRGS)

Endereço: Av. João Pessoa, 52/53, Centro - Porto Alegre/RS - Brasil

CEP: 90040-000 - E-mail: ricardo.dathein@ufrgs.br

Recebido em 14 de agosto de 2012. Aceito em 16 de julho de 2014.

\begin{abstract}
Resumo
O artigo analisa a influência do comportamento inovativo das grandes empresas da indústria de transformação brasileira sobre a formação do Sistema Nacional de Inovação (SNI), utilizando-se da base de dados das PINTECs (2000, 2003, 2005 e 2008), a partir da construção de indicadores relativos à responsabilidade pelo desenvolvimento de produto e/ou processo; localização e importância das fontes de informação; relações de cooperação; esforço inovativo e qualificação das pessoas ocupadas em atividades de P\&D. Conforme os indicadores considerados, as empresas estrangeiras têm inovado, predominantemente, a partir de relações intra-corporativas, caracterizando-se por um comportamento "hierarquicamente integrado", com "reação adaptativa" ao que acontece em âmbito internacional; por sua vez, as grandes empresas nacionais, em regra, têm inovado relativamente menos, além de se caracterizarem como "seguidoras" das estratégias inovativas das empresas estrangeiras. Nesse sentido, conclui-se que o comportamento inovativo desses dois grupos de empresas não tem favorecido o desenvolvimento do SNI brasileiro.
\end{abstract}

\section{Palavras-Chave}

Sistema Nacional de Inovação. Comportamento inovativo. Grandes empresas. Economia brasileira.

\begin{abstract}
The article analyses the influence of the innovative behavior adopted by large companies in Brazilian processing industry over the formation of the National System of Innovation (NSI) using PINTEC's database (2000, 2003, 2005 and 2008) and from the generation of indicators that measure the responsibility for product and/or process development,

- Agradecemos ao IBGE por fornecer tabulações especiais das PINTECs, o que possibilitou a realização deste trabalho, e também a dois pareceristas anônimos da Revista por sua análise crítica.
\end{abstract}


from localization and importance of information sources, cooperation relations, innovative effort and the qualification of people involved in P\&D activities. According to the studied indicators, foreign companies innovate predominantly from intracompany relations, adopting a "hierarchically integrated" behavior with "adaptive reaction" to what happens internationally. In turn, large national companies, as a rule, innovate relatively less apart can be characterized as "followers" of the innovative strategies of foreign companies. To this effect, we conclude that the innovative behavior of these two company groups has not helped the development of Brazilian NSI.

\section{Keywords}

National Innovation System. Innovative behavior. Large enterprises. Brazilian economy.

\section{JEL Classification}

F23. 019.

\section{Introdução}

Comparado com alguns países desenvolvidos e em desenvolvimento, o "sistema de ciência e tecnologia" brasileiro (medido em termos de gastos em $\mathrm{P} \& \mathrm{D}$, registro de patentes, produção científica e qualificação dos recursos humanos) caracterizaria, conforme Albuquerque (1995), a existência de um sistema nacional de inovação (SNI) incompleto. Em linhas gerais, alguns resultados obtidos a partir das Pesquisas de Inovação Tecnológica (PINTEC/IBGE) (De Negri; Salerno, 2005; De Negri, 2007; Zucoloto, 2009; CGEE-ANPEI, 2009 entre outros) têm corroborado a condição de incompletude mais do que a de inexistência de um SNI brasileiro, à medida que se adota o conceito conforme a amplitude de seu significado (Freeman, 1995; Nelson, 1996; Edquist, 2001; Lundvall, 2007).

Este artigo visa a avaliar a importância da ação das grandes empresas nacionais e estrangeiras para o desenvolvimento do SNI no Brasil, a partir das principais atividades econômicas da indústria de transformação, em virtude da participação dessas empresas na economia nacional, sobretudo no período mais recente, inclusive no que se refere aos processos inovativos. Considera-se que a consolidação de um SNI é resultado das interações entre diferentes organizações, cujas atividades, pelo menos parcialmente, têm caráter inovativo. 
A questão é justamente saber em que medida o comportamento inovativo das grandes empresas nacionais e estrangeiras ${ }^{1}$ (500 e mais pessoas ocupadas) pode ser associado ao desenvolvimento de um SNI na economia brasileira.

A abordagem tem como pressuposto fundamental a importância das empresas transnacionais (ETNs) para a formação de SNIs em uma economia globalizada (Freeman, 1995), sobretudo a partir da perspectiva histórica de desenvolvimento econômico de um país retardatário, cuja estrutura produtiva industrial é marcada pela crescente participação dessas empresas, como no caso brasileiro.

Apesar da multiplicidade de relações que, somadas às idiossincrasias inerentes a um SNI, dificultam uma análise de forma detalhada, é possível obter uma compreensão de seu desenvolvimento através de indicadores que associam as inovações ao desenvolvimento econômico nacional, em que as empresas, sobretudo de grande porte, são consideradas agentes fundamentais desse processo. Para tanto, são apresentados indicadores quantitativos que permitem relacionar o comportamento inovativo das grandes empresas à consolidação de um SNI no Brasil, visando melhor compreender em que medida o comportamento inovativo daquelas tem afetado o desenvolvimento desse, no passado recente. $\mathrm{O}$ mapeamento permite avaliar de que forma as principais características (tamanho, recursos humanos qualificados, esforço inovativo, fontes de informação, responsabilidades pela inovação e relações de cooperação) das grandes empresas inovadoras, nacionais e estrangeiras, da indústria de transformação brasileira, sinalizam para uma contribuição para o desenvolvimento do SNI brasileiro. A opção pelas grandes empresas se dá em função de que essas possuem taxas de inovação (percentual das empresas que implementaram inovações - produto e/ou processo tecnologicamente novo ou substancialmente aprimorado - em relação ao total das empresas) mais elevadas, ${ }^{2}$ bem como fazem parte do "estrato

l Conforme a metodologia da PINTEC, capital controlador é aquele que é titular de uma participação no capital social que lhe assegura a maioria dos votos e que, portanto, possui direitos permanentes de eleger os administradores e de preponderar nas deliberações sociais, ainda que não exerça este direito, ausentando-se das assembléias ou nelas abstendo-se de votar. O capital controlador pode ser nacional, estrangeiro ou nacional e estrangeiro (IBGE, 2007). Nesse artigo são analisados os comportamentos das empresas com capital controlador estrangeiro (grandes empresas estrangeiras) e nacional (grandes empresas nacionais).

2 Conforme dados das PINTECs, a taxa de inovação da indústria de transformação brasileira foi de 31,5\%, no triênio 1998-2000, mantendo-se na casa dos 33\% entre 2001 e 2005, e subindo para 38,4\% entre 2006 e 2008. Para as grandes empresas, as taxas de inovação nesses mesmos períodos foram, respectivamente, $75,7 \%, 72,5 \%, 79,2 \%$ e $72,2 \%$. 
certo" ${ }^{3}$ das PINTECs. Em virtude das limitações na disponibilidade de informações, foram consideradas nesse artigo 13 das 23 atividades econômicas disponíveis, a dois dígitos (CNAE). Ressalte-se que essas 13 atividades foram responsáveis por mais de 90\% dos investimentos estrangeiros diretos (IEDs) realizados na economia brasileira no período analisado (BCB, 2010).

A próxima seção trata da importância das ETNs para a formação dos SNIs das economias em desenvolvimento, num contexto de crescente globalização econômica. A terceira seção analisa um conjunto de indicadores, baseados nas PINTECs, compreendendo o período 1998-2008, ${ }^{4}$ que refletem o comportamento inovativo das grandes empresas, nacionais e estrangeiras, da indústria de transformação brasileira. Na quarta seção são apresentadas as considerações finais.

\section{SNI e ETNs em economias em desenvolvimento}

Para Nelson (1996), sistema trata de atores institucionais que, atuando conjuntamente, afetam o desempenho inovador das economias e, por conseguinte, o seu processo de desenvolvimento. Já na perspectiva de Edquist (2001), sistema seria uma reunião de diferentes componentes, relacionados entre si, dado um determinado contexto (espacial, setorial e funcional) e, por sua vez, inovações seriam criações com significado econômico; não existiria, portanto, um modelo de SNI a ser adotado, nem a necessidade de que ele se estabeleça a partir de inovações radicais, na fronteira do conhecimento (Lundvall, 2007). Cada economia constrói seu próprio SNI, a partir das suas idiossincrasias relativas às formas como os agentes da inovação interagem, levando em consideração os arranjos institucionais vigentes.

Ernst (2000) chama a atenção para as dificuldades enfrentadas pelos países em desenvolvimento para promover um sistema nacional de inovação, em função de que suas estruturas produtivas estão geralmente integradas a empresas sediadas em outros países. Apesar

3 Todas as empresas com 500 e mais pessoas ocupadas (estrato certo) são pesquisadas em todas as PINTECs; para as demais empresas os dados são obtidos por amostragem.

4 Não foi possível o uso dos resultados da PINTEC 2011, pois, segundo a Diretoria de Pesquisas do IBGE, devido à má qualidade do Coeficiente de Variação (CV) das tabelas, várias aberturas de atividades não podem ser feitas, fundamentalmente para empresas estrangeiras. Por isso, o número de setores analisados diminuiria ainda mais. 
disso, o autor identifica um movimento favorável à dispersão das atividades inovativas na direção de países em desenvolvimento (notadamente do leste asiático). Na busca de ativos complementares, as ETNs estariam ampliando suas "redes de produção global", transformando-se, efetivamente, em "corporações internacionalizadas" (network flagships), através do processo de "dispersão concentrada" das suas atividades.

Neste mesmo sentido, Freeman (1995) observa que tem crescido a importância das condições nacionais para a atração/utilização de IEDs voltados à inovação. Trata-se de uma questão tecnológica, organizacional e institucional; portanto, da necessidade de coevolução (Nelson, 2002) dessas diferentes estruturas condicionantes dos processos inovativos, principalmente no que se refere à interação das grandes empresas com outros agentes da inovação.

A cooperação ${ }^{5}$ em regra sob a liderança das grandes empresas, estabelece as bases de uma relação econômica "extra-mercado", em que o processo de aprendizado, ${ }^{6}$ sobretudo em sua dimensão interativa, é um dos mecanismos que viabilizam as demais inovações, a partir das inovações organizacionais (rede de empresas etc.). Quanto mais ampla e aprofundada for a troca de informações e conhecimentos (codificado e tácito), maior tenderia a ser a importância da coope-

5 Nesse artigo o termo cooperação será utilizado com o significado de interação entre diferentes agentes, visando benefícios mútuos. Nesse sentido, é sinônimo de "parceria". Para o IBGE (2007), "cooperação para a inovação" consiste na "[...] participação ativa em projetos conjuntos de $\mathrm{P} \& \mathrm{D}$ e outros projetos de inovação com outra organização (empresa ou instituição), não implicando, necessariamente, que as partes envolvidas obtenham benefícios comerciais imediatos".

6 São vários os tipos de aprendizado relacionados às atividades das empresas: learning-bydoing, leaning-by-operating, learning-by-changing, learning-by-training, learning-by-hiring, learning-by-searching, learning-by-using, learning-by-interact, learning from advances in science and technology, learning from inter-industry spillover, individual, organizational and institutional learning e assim por diante. Neste artigo, será dado ênfase ao aspecto interativo do processo de aprendizado. Obviamente que a dimensão do sentido de aprendizado não permite uma divisão estanque em relação à tipologia, o que implica em conceber o aprendizado como um processo, individual e coletivo, que abrange as diferentes formas de geração, utilização e difusão do conhecimento. Seguindo a proposição de Lundvall (2007), entendese que aprendizado é um processo de adaptação, mas também de "construção de competências", que promove melhorias na capacidade de resolução de problemas, para indivíduos e organizações, onde a interação entre os diferentes agentes da inovação desempenha um papel fundamental. Segundo Johnson e Lundvall (2005, p. 86-7): "A principal razão pela qual o aprendizado tornou-se mais importante é a dialética entre aprendizado e conhecimento. [...] Aprendizado refere-se ao desenvolvimento de novas competências e ao estabelecimento de novas capacitações, e não apenas ao 'acesso a novas informações'. A economia do aprendizado não é necessariamente uma economia de alta tecnologia. $\mathrm{O}$ aprendizado é uma atividade que ocorre em todas as áreas da economia [...]." 
ração para o desenvolvimento do SNI; no sentido oposto, as restrições ao desenvolvimento de relações de cooperação entre diferentes organizações, tenderia a limitar os efeitos de transbordamento do conhecimento.

Analisar o processo de aprendizado interativo, como aspecto fundamental da difusão do conhecimento, implica tratar das questões relativas às dimensões interempresas, que são fundamentalmente estabelecidas a partir de seu ambiente de seleção, o que também é um ambiente de cooperação (ou de competição-cooperativa). Aumentar a capacidade de adaptação às mudanças na demanda, no "paradigma tecno-econômico das redes flexíveis" (Perez, 2001), obrigou as empresas, sobretudo de grande porte, a reelaborar as suas formas organizacionais, criando uma maior necessidade de ampliação e aprofundamento das suas relações de cooperação. A interatividade dos processos inovativos, a partir das capacitações desenvolvidas nos processos de aprendizado, apresenta-se como um dos resultados possíveis de se observar nas "redes de empresas", inclusive no que se refere à subcontratação (Carleial, 2001).

O desenvolvimento da interação entre empresas (e outros agentes da inovação) nacionais e estrangeiras, sob a forma de cooperação, constitui-se em um importante indicador de que as filiais de ETNs têm potencial para atuar junto ao desenvolvimento de um SNI. Neste sentido, as inovações, em parte estabelecidas a partir da cooperação, têm sido fundamentais para criar condições para que as empresas nacionais utilizem, adaptem e, em menor grau, desenvolvam os mecanismos relacionados aos aspectos tecnológicos e organizacionais (Cimoli et al., 2007).

Neste contexto, o aprendizado por interação tem sido um importante indicador da dimensão institucional de um SNI. As "tecnologias sociais institucionalizadas" (Nelson, 2008), desenvolvidas a partir das inovações organizacionais (as redes de empresas são um exemplo no atual paradigma tecno-econômico), com forte influência das ETNs, passariam a exercer uma influência direta sobre o comportamento das demais empresas, sobretudo das grandes empresas nacionais, que costumam ser adeptas de "estratégias seguidoras" (Sarti; Laplane, 2002; Araújo, 2005). 
A busca pela maior flexibilidade, interna (organização da produção) e externa (divisão do trabalho, via cooperação etc.), é intrínseca ao processo de desverticalização da grande empresa, o que contribui para a promoção do SNI, na medida em que as organizações locais passam a fazer parte da "rede". No entanto, faz-se necessário que as "parcerias" envolvam atividades inovativas, com perspectivas de ganhos mútuos (Coriat, 1991).

No caso da economia brasileira, a diversidade do setor industrial, aliada à participação histórica, e em vários casos majoritária das ETNs em grande parte de seus ramos de atividade, por um lado, amplia as possibilidades de adoção de estratégias de desenvolvimento do SNI, como forma de utilizar as potencialidades dos IEDs - inclusive no que se refere ao acesso ao desenvolvimento tecnológico internacional, em virtude da crescente globalização das atividades produtivas e também inovativas; por outro lado, tende a vincular o desenvolvimento do SNI às estratégias das ETNs, cuja autonomia é apenas parcialmente condicionada pelas políticas nacionais dos países hospedeiros.

Tendo em vista que as inovações são cada vez mais resultado de processos interativos, que extrapolam as fronteiras da empresa e da indústria, havia a expectativa de que a diversidade do parque industrial brasileiro aumentasse o potencial de criação e desenvolvimento de seu SNI, a partir das relações entre seus diferentes atores, inclusive e a partir da predominância do capital estrangeiro em atividades econômicas de intensidade tecnológica mais elevada. Ao expandirem seus IEDs em P\&D, as ETNs ampliariam as possibilidades de criação de "sistemas de inovação abertos", dada a tendência à crescente facilidade de atuação em redes de cooperação (UNCTAD, 2005). Promover inovações, através de redes globais de criação e difusão do conhecimento, tem sido uma importante estratégia de desenvolvimento econômico, o que vem acentuando a importância da atuação das ETNs em uma área até pouco tempo restrita às suas matrizes. Ressalte-se que a velocidade e a forma como se dá esse processo é bastante variada, como observa a UNCTAD (2005). No entanto, o fato de que as relações de cooperação têm se apresentado como uma importante forma de promoção de inovações no atual paradigma tecno-econômico, inclusive no que se refere ao estreitamento das relações entre empresas nacionais e estrangeiras em países em desenvolvimento, não significa que essas economias tenham sido efetivamente favorecidas nesse processo. 
Historicamente, os principais países latino-americanos (Argentina, Brasil e México) têm se caracterizado pela crescente participação das ETNs em sua estrutura produtiva industrial, o que não tem se refletido em aumento da importância destas empresas para o desenvolvimento de seus SNIs (Katz, 2005).

A "convergência tecnológica", fundamental para o desenvolvimento dos países retardatários e vista, sob um prisma ortodoxo (neoclássico), como algo que tende a se difundir rapidamente nos países receptores, não tem sido observada ao longo do tempo, ainda que a transnacionalização das economias periféricas tenha se intensificado a partir do final do século XX. Nesse cenário, tornou-se fundamental que os países seguidores criassem condições para desenvolver uma base científico-tecnológica própria, ainda que em grande parte isso se dê a partir de estratégias imitadoras. Como regra, dado a incipiente base técnica e científica dos países hospedeiros retardatários, as ETNs tenderiam a realizar P\&D adaptativo, seguindo uma orientação de indução pela demanda (demand pull), adotando uma estratégia de "duplicação" (principalmente de processos produtivos) (Ruiz, 2007).

Depreende-se desse contexto que o processo de "convergência tecnológica" dos países retardatários é caracterizado por uma dupla dependência: externa, em função do acesso à tecnologia e ao conhecimento; e interna (country-specific), em função da criação de condições que permitam a evolução do processo de aprendizado e da difusão do conhecimento, intra e entre as diferentes atividades econômicas.

Em relação às expectativas dos "efeitos de transbordamento" produtivos, mas principalmente tecnológicos, associados ao crescimento dos IEDs, a partir de meados da década de 1990, Laplane e Sarti (1999, p. 264) afirmam que: "Os encadeamentos tecnológicos são limitados pela especialização crescente das filiais locais, que suprem suas necessidades de tecnologia com soluções geradas nos centros especializados mantidos pelas matrizes no exterior." Dessa forma, a ênfase na busca de mercado e de recursos naturais (CEPAL, 2004), adotada pelas filiais de ETNs na indústria de transformação brasileira, significa um baixo nível de "transbordamento" do processo de aprendizado. Além disso, a estratégia de fornecimento global (global sourcing) adotada pelas ETNs no Brasil nos anos 1990, segundo Laplane e Sarti (1999), contribuiu para a redução do índice de nacionalização das empresas de bens finais, bem como para a substituição de fornecedores locais por estrangeiros. 
De acordo com Rodríguez (2002), faltou às economias periféricas, como a brasileira, um "embasamento institucional" adequado, que garantisse a atualização dos processos inovativos, ou seja, que contribuísse para o avanço do SNI na transição de paradigmas tecno -econômicos. A instabilidade macroeconômica da década de 1980, que se estendeu durante os primeiros anos da década seguinte, viria a agravar ainda mais esta condição de atraso tecnológico e de quase inexistência de articulações em torno do SNI.

Essa situação tendia a se agravar à medida que, ao contrário do ocorrido durante o PSI, onde houve uma forte intervenção do Estado sobre os rumos (setoriais) dos investimentos, na década de 1990, num processo seletivo centrado no mercado, as empresas adotaram uma postura individualizada em busca da convergência produtiva, tecnológica e organizacional. Nesse processo, as empresas estrangeiras levaram vantagem (Castro, 2003). É importante saber em que medida esta "vantagem" beneficiou o desenvolvimento do SNI brasileiro.

\section{O comportamento inovativo das grandes empresas da indústria de transformação brasileira entre 1998 e 2008}

A análise das relações que as empresas estrangeiras mantêm com organizações nacionais e internacionais (empresas, institutos, governos etc.), serve como uma aproximação para o entendimento dos efeitos que aquelas exercem na difusão do conhecimento e no aprendizado interativo $^{7}$ na economia nacional. Por sua vez, o comportamento inovativo das grandes empresas nacionais é usado como referência para a análise do papel desempenhado pelas estrangeiras, avaliado a partir da construção de indicadores baseados nos dados das PINTECs dos anos de 2000, 2003, 2005 e 2008.

As grandes empresas estrangeiras possuem um elevado nível de participação na indústria nacional, entre aquelas que implementaram inovações (Tabela 1), o que as torna agentes em potencial do desenvolvimento do SNI brasileiro, podendo ser avaliado a partir da análise de alguns indicadores.

7 Como observa Lundvall (2007, p. 28): "Empirical studies show that networking and interactive learning across organizational borders are important prerequisites for successful innovation." 
Tabela 1 - Número de empresas nacionais e estrangeiras, com 500 e mais pessoas ocupadas, que implementaram inovaçóes, por atividades selecionadas da indústria de transformação, conforme níveis de intensidade tecnológica - Brasil- 1998-2008.

\begin{tabular}{|c|c|c|c|c|c|c|c|c|}
\hline \multirow{2}{*}{$\begin{array}{l}\text { Indústria de transformação } \\
\text { Atividade econômica }\end{array}$} & \multicolumn{4}{|c|}{ Nacional } & \multicolumn{4}{|c|}{ Estrangeira } \\
\hline & $1998 / 2000$ & $2001 / 2003$ & $2003 / 2005$ & $2006 / 2008$ & $1998 / 2000$ & $2001 / 2003$ & $2003 / 2005$ & $2006 / 2008$ \\
\hline \multicolumn{9}{|c|}{ Baixa e média-baixa intensidade tecnológica } \\
\hline Alimentos e bebidas & 159 & 166 & 232 & 204 & 27 & 32 & 41 & 55 \\
\hline Produtos têxteis & 57 & 50 & 58 & 61 & 6 & n.d. & n.d. & 7 \\
\hline Celulose e papel & 24 & 25 & 27 & 32 & 11 & n.d. & 12 & 8 \\
\hline $\begin{array}{l}\text { Artigos de borracha } \\
\text { e plásticos }\end{array}$ & 25 & 26 & 42 & 35 & 10 & n.d. & 13 & 16 \\
\hline Minerais não-metálicos & 22 & 30 & 33 & 34 & 8 & n.d. & 12 & 13 \\
\hline Metalurgia básica & 21 & 23 & 37 & 40 & 13 & 13 & 11 & 16 \\
\hline Produtos de metal & 36 & 27 & 29 & 36 & 5 & n.d. & n.d. & 9 \\
\hline Móveis e indústrias diversas & 34 & 34 & 35 & 35 & 7 & n.d. & n.d. & 5 \\
\hline \multicolumn{9}{|c|}{ Alta e média-alta intensidade tecnológica } \\
\hline Produtos químicos & 51 & 51 & 56 & 53 & 46 & 42 & 48 & 46 \\
\hline Máquinas e equipamentos & 32 & 36 & 44 & 41 & 34 & 38 & 39 & 31 \\
\hline $\begin{array}{l}\text { Máquinas, aparelhos e } \\
\text { materiais elétricos }\end{array}$ & 13 & 18 & 16 & 23 & 24 & 18 & 24 & 24 \\
\hline Eletrônico e comunicações & 14 & n.d. & n.d. & 20 & 19 & 19 & 14 & 27 \\
\hline $\begin{array}{l}\text { Veículos automotores, } \\
\text { reboques e carrocerias }\end{array}$ & 35 & 27 & 36 & 45 & 51 & 42 & 50 & 59 \\
\hline
\end{tabular}

Nota: n.d. $=$ dados não disponíveis

Fonte de dados: PINTECs 2000, 2003, 2005 e 2008 (tabulações especiais).

A "responsabilidade" pelo desenvolvimento de produto e/ou processo, assim como as "fontes de informação" das grandes empresas que implementaram inovações no período 1998-2008, são indicadores que revelam em que medida essas empresas concentraram (na própria empresa e/ou na corporação) as suas atividades inovativas. Por sua vez, as "relações de cooperação" indicam em que medida as empresas têm desenvolvido atividades inovativas de forma interativa, contribuindo para a difusão do conhecimento.

Neste sentido, as informações relacionadas à concentração das atividades inovativas, permite que se avaliem importantes aspectos da dimensão interativa do processo de aprendizado. Ressalte-se que o processo de aprendizado é parte integrante, e indispensável, do pro- 
cesso de inovação, ao mesmo tempo em que a sua dimensão interativa é um componente fundamental do desenvolvimento do SNI, à medida que está diretamente associado à difusão do conhecimento.

Considera-se que as inovações se tornam mais importantes para as economias quando são geradas e difundidas a partir do território nacional, ainda que em parte estejam vinculadas às atividades das empresas estrangeiras. Em sentido oposto, ao serem introduzidas do exterior, as inovações tendem a exercer efeitos limitados sobre o processo de aprendizado e a difusão do conhecimento, de forma que restringem as possibilidades de desenvolvimento do SNI. Por este motivo, depreende-se que, por mais que se conceba a importância dos "sistemas de inovação abertos" (UNCTAD, 2005), como alternativas de desenvolvimento para economias retardatárias, as inovações continuam tendo um importante conteúdo local (country) específico, por envolverem um conjunto de fatores que extrapolam os aspectos estritamente tecnológicos e o acesso à informação, além de serem também de natureza institucional (Nelson, 2002).

\subsection{Responsabilidade pelo desenvolvimento de produto elou processo}

No caso das grandes empresas nacionais (Tabela 2), a própria empresa aparece como o principal responsável pelo desenvolvimento de inovações de produto, em todas as atividades selecionadas e em todo o período considerado. Além disso, em nove das treze atividades consideradas, a responsabilidade da própria empresa aumentou entre 2000 e 2008. 
Tabela 2 - Principal responsável pelo desenvolvimento de produto nas empresas nacionais com 500 e mais pessoas ocupadas que implementaram inovações, por atividades selecionadas da indústria de transformação - Brasil- 1998-2008 (em \%)

\begin{tabular}{|c|c|c|c|c|c|c|c|c|c|c|c|c|c|c|c|c|}
\hline \multirow{2}{*}{$\begin{array}{l}\text { Indústria de } \\
\text { transformação } \\
\text { Atividade } \\
\text { econômica }\end{array}$} & \multicolumn{4}{|c|}{ A empresa } & \multicolumn{4}{|c|}{$\begin{array}{l}\text { Outra empresa } \\
\text { do grupo }\end{array}$} & \multicolumn{4}{|c|}{$\begin{array}{c}\text { A empresa em } \\
\text { cooperação c/ outras } \\
\text { empresas ou institutos }\end{array}$} & \multicolumn{4}{|c|}{$\begin{array}{l}\text { Outras empresas } \\
\text { ou institutos }\end{array}$} \\
\hline & $\begin{array}{l}1998 / \\
2000 \\
\end{array}$ & $2001 /$ & 2003 & 2006 & 1998 & $2001 /$ & $2003 /$ & 2006 & $\begin{array}{l}1998 \\
2000\end{array}$ & $2001 /$ & $2003 /$ & $2006 /$ & $\begin{array}{l}1998 / \\
2000\end{array}$ & $2001 /$ & 2003 & 2006 \\
\hline \multicolumn{17}{|c|}{ Baixa e média-baixa intensidade tecnológica } \\
\hline Alimento & 65,9 & 80,5 & 74,1 & 79,8 & 1,2 & 1,7 & 0,7 & 6,4 & 25,1 & 10,2 & 12,9 & 10,2 & 7,8 & 7,6 & 12,2 & 3,6 \\
\hline Produtos têxteis & 73,5 & 67,4 & 66,7 & 72,9 & 0,0 & 2,8 & 0,0 & 0,0 & 14,7 & 16,2 & 15,6 & 20,8 & 11,8 & 13,7 & 17,8 & 6,3 \\
\hline Celulose e papel & 66,1 & 58,0 & 82,9 & 80,0 & 0,0 & 5,3 & 5,6 & 5,0 & 26,7 & 36,7 & 11,1 & 10,0 & 7,2 & 0,0 & 0,0 & 5,0 \\
\hline $\begin{array}{l}\text { Artigos de borracha } \\
\text { e plásticos }\end{array}$ & 68,4 & 95,0 & 72,7 & 74,1 & 0,0 & 5,0 & 0,0 & 3,7 & 21,1 & 0,0 & 21,2 & 11,1 & 10,5 & 0,0 & 6,1 & 11,1 \\
\hline Minerais não-metálicos & 61,1 & 65,4 & 81,5 & 88,9 & 0,0 & 3,8 & 3,7 & 0,0 & 23,3 & 19,2 & 11,1 & 11,1 & 15,5 & 11,5 & 3,7 & 0,0 \\
\hline Metalurgia básica & 71,5 & 57,1 & 64,0 & 70,4 & 0,0 & 7,1 & 4,0 & 7,4 & 21,3 & 28,6 & 28,0 & 18,5 & 7,1 & 7,1 & 4,0 & 3,7 \\
\hline Produtos de metal & 65,9 & 65,0 & 70,6 & 87,0 & 3,8 & 0,0 & 0,0 & 4,3 & 18,8 & 15,0 & 23,5 & 8,7 & 11,5 & 20,0 & 5,9 & 0,0 \\
\hline $\begin{array}{l}\text { Móveis e indústrias } \\
\text { diversas }\end{array}$ & 70,0 & 65,7 & 82,6 & 80,6 & 3,3 & 0,0 & 4,3 & 0,0 & 6,7 & 28,3 & 8,7 & 12,9 & 20,0 & 8,0 & 4,3 & 6,5 \\
\hline \multicolumn{17}{|c|}{ Alta e média-alta intensidade tecnológica } \\
\hline Produtos químicos & 67,1 & 68,1 & 82,4 & 80,9 & 5,1 & 2,3 & 3,9 & 2,1 & 22,7 & 27,4 & 13,7 & 6,4 & 5,1 & 2,2 & 0,0 & 10,6 \\
\hline $\begin{array}{l}\text { Máquinas e equipa- } \\
\text { mentos }\end{array}$ & 75,4 & 70,6 & 78,0 & 69,0 & 0,0 & 0,0 & 2,4 & 6,9 & 15,1 & 16,3 & 14,6 & 24,1 & 9,5 & 13,1 & 4,9 & 0,0 \\
\hline $\begin{array}{l}\text { Máquinas, aparelhos e } \\
\text { materiais elétricos }\end{array}$ & 66,5 & 64,7 & 84,6 & 88,9 & 0,0 & 0,0 & 0,0 & 5,6 & 33,5 & 35,3 & 15,4 & 5,6 & 0,0 & 0,0 & 0,0 & 0,0 \\
\hline $\begin{array}{l}\text { Eletrônico e comuni- } \\
\text { cações }\end{array}$ & 53,8 & n.d. & n.d. & 52,6 & 0,0 & n.d. & n.d. & 5,5 & 30,8 & n.d. & n.d. & 26,1 & 15,4 & n.d. & n.d. & 15,8 \\
\hline $\begin{array}{l}\text { Veículos automotores, } \\
\text { reboques e carrocerias }\end{array}$ & 58,4 & 50,4 & 67,9 & 70,7 & 0,0 & 4,8 & 3,6 & 2,4 & 32,9 & 36,1 & 25,8 & 24,4 & 8,7 & 8,8 & 4,4 & 2,4 \\
\hline
\end{tabular}

Nota: n.d.= dados não disponíveis.

Fonte de dados: PINTECs 2000, 2003, 2005 e 2008 (tabulações especiais)

Para as empresas estrangeiras (Tabela 3), ainda que a maior parte das atividades inovativas tenha sido concentrada na empresa, a responsabilidade pelo desenvolvimento de produtos foi mais compartilhada, ganhando importância, sobretudo, as atividades intra-corporativas ("outra empresa do grupo"). 
Tabela 3 - Principal responsável pelo desenvolvimento de produto, nas empresas estrangeiras com 500 e mais pessoas ocupadas, que implementaram inovações, por atividades selecionadas da indústria de transformação - Brasil- 1998-2008 (em \%)

\begin{tabular}{|c|c|c|c|c|c|c|c|c|c|c|c|c|c|c|c|c|}
\hline \multirow{2}{*}{$\begin{array}{l}\text { Indústria de } \\
\text { transformação } \\
\text { Atividade } \\
\text { econômica }\end{array}$} & \multicolumn{4}{|c|}{ A empresa } & \multicolumn{4}{|c|}{ Outra empresa do grupo } & \multicolumn{4}{|c|}{$\begin{array}{c}\text { A empresa em } \\
\text { cooperação c/ outras } \\
\text { empresas ou institutos }\end{array}$} & \multicolumn{4}{|c|}{$\begin{array}{l}\text { Outras empresas } \\
\text { ou institutos }\end{array}$} \\
\hline & $\begin{array}{l}1998 / \\
2000\end{array}$ & $\begin{array}{l}2001 / \\
2003\end{array}$ & $\begin{array}{l}2003 / \\
2005\end{array}$ & $2006 /$ & $\begin{array}{l}1998 / \\
2000\end{array}$ & $2001 /$ & \begin{tabular}{|l|}
$2003 /$ \\
2005
\end{tabular} & $\begin{array}{l}2006 / \\
2008\end{array}$ & $\begin{array}{l}1998 / \\
2000\end{array}$ & $\begin{array}{l}2001 / \\
2003\end{array}$ & $\begin{array}{l}2003 / \\
2005\end{array}$ & $2006 /$ & $\begin{array}{l}1998 / \\
2000\end{array}$ & $2001 /$ & 2003/ & $2006 /$ \\
\hline \multicolumn{17}{|c|}{ Baixa e média-baixa intensidade tecnológica } \\
\hline $\begin{array}{l}\text { Alimentos e } \\
\text { bebidas }\end{array}$ & 68,0 & 64,2 & 67,7 & 71,5 & 10,7 & 8,0 & 16,1 & 13,0 & 21,3 & 19,7 & 16,1 & 12,8 & 0,0 & 8,0 & 0,0 & 2,7 \\
\hline Produtos têxteis & 40,0 & n.d. & n.d. & 50,0 & 20,0 & n.d. & n.d. & 16,8 & 40,0 & n.d. & n.d. & 33,3 & 0,0 & n.d. & n.d. & 0,0 \\
\hline Celulose e papel & 37,5 & n.d. & 54,5 & 71,1 & 12,5 & n.d. & 18,2 & 14,4 & 25,0 & n.d. & 9,1 & 15,4 & 25,0 & n.d. & 18,2 & 0,0 \\
\hline $\begin{array}{l}\text { Artigos de borra- } \\
\text { cha e plásticos }\end{array}$ & 75,0 & n.d. & 50,0 & 60,0 & 25,0 & n.d. & 25,0 & 26,7 & 0,0 & n.d. & 25,0 & 6,7 & 0,0 & n.d. & 0,0 & 6,7 \\
\hline $\begin{array}{l}\text { Minerais não- } \\
\text {-metálicos }\end{array}$ & 40,0 & n.d. & 54,5 & 87,5 & 40,0 & n.d. & 36,4 & 0,0 & 0,0 & n.d. & 9,1 & 12,5 & 20,0 & n.d. & 0,0 & 0,0 \\
\hline Metalurgia básica & 75,0 & 32,9 & 33,3 & 63,6 & 12,5 & 11,0 & 33,3 & 9,1 & 12,5 & 43,9 & 33,3 & 27,3 & 0,0 & 12,2 & 0,0 & 0,0 \\
\hline Produtos de metal & 48,9 & n.d. & n.d. & 29,6 & 51,1 & n.d. & n.d. & 42,9 & 0,0 & n.d. & n.d. & 14,3 & 0,0 & n.d. & n.d. & 14,3 \\
\hline $\begin{array}{l}\text { Móveis e indústrias } \\
\text { diversas }\end{array}$ & 33,3 & n.d. & n.d. & 25,0 & 16,7 & n.d. & n.d. & 50,0 & 33,3 & n.d. & n.d. & 25,0 & 0,0 & n.d. & n.d. & 0,0 \\
\hline \multicolumn{17}{|c|}{ Alta e média-alta intensidade tecnológica } \\
\hline Produtos químicos & 43,0 & 48,6 & 50,0 & 46,2 & 39,8 & 32,3 & 31,0 & 41,0 & 2,8 & 19,1 & 11,9 & 12,8 & 14,4 & 0,0 & 7,1 & 0,0 \\
\hline $\begin{array}{l}\text { Máquinas e } \\
\text { equipamentos }\end{array}$ & 50,0 & 61,6 & 54,5 & 45,8 & 33,3 & 17,2 & 30,3 & 41,7 & 10,0 & 21,1 & 12,1 & 8,3 & 6,7 & 0,0 & 3,0 & 4,2 \\
\hline $\begin{array}{l}\text { Máquinas, apare- } \\
\text { lhos e materiais } \\
\text { elétricos }\end{array}$ & 50,2 & 46,8 & 47,6 & 68,2 & 24,7 & 33,2 & 38,1 & 22,7 & 15,1 & 13,4 & 9,5 & 9,1 & 10,0 & 6,7 & 4,8 & 0,0 \\
\hline $\begin{array}{l}\text { Eletrônico e } \\
\text { comunicações }\end{array}$ & 50,8 & 23,4 & 8,3 & 34,1 & 27,3 & 36,3 & 25,0 & 57,2 & 0,0 & 34,5 & 25,0 & 4,5 & 21,9 & 5,7 & 41,7 & 4,2 \\
\hline $\begin{array}{l}\text { Veículos automo- } \\
\text { tores, reboques e } \\
\text { carrocerias }\end{array}$ & 27,9 & 22,8 & 41,1 & 60,0 & 31,0 & 31,3 & 21,2 & 24,0 & 32,7 & 37,4 & 32,1 & 16,0 & 8,4 & 8,6 & 4,7 & 0,0 \\
\hline
\end{tabular}

Nota: n.d.= dados não disponíveis.

Fonte de dados: PINTECs 2000, 2003, 2005 e 2008 (tabulações especiais).

No que se refere à "cooperação com outras empresas ou institutos", entre as estrangeiras, o destaque fica por conta das grandes empresas que produziram veículos automotores, reboques e carrocerias (19982005); ressalte-se que esta atividade, em que a busca de mercado é considerada uma estratégia fundamental para as empresas (CEPAL, 2004), apresentou elevado esforço inovativo na aquisição de máquinas e equipamentos (2000, 2003 e 2005) (Tabela 13) combinado com elevados níveis de comércio intra-firma $(77,8 \%$ das exportações e 70,5\% das importações, em 2005) (BCB, 2010). 
Em relação à responsabilidade pelo desenvolvimento de processos (Tabela 4), nas grandes empresas nacionais que implementaram inovações, entre 1998-2008, o destaque fica por conta de "outras empresas ou institutos", com significativa redução da importância da própria empresa. A "cooperação com outras empresas", ainda que relevante, aparece, em regra, na terceira posição como principal forma de "responsabilidade".

Tabela 4 - Principal responsável pelo desenvolvimento de processo nas empresas nacionais com 500 e mais pessoas ocupadas que implementaram inovações, por atividades selecionadas da indústria de transformação - Brasil- 1998-2008 (em \%)

\begin{tabular}{|c|c|c|c|c|c|c|c|c|c|c|c|c|c|c|c|c|}
\hline \multirow{2}{*}{$\begin{array}{l}\text { Indústria de } \\
\text { transformação } \\
\text { Atividade econômica }\end{array}$} & \multicolumn{4}{|c|}{ A empresa } & \multicolumn{4}{|c|}{ Outra empresa do grupo } & \multicolumn{4}{|c|}{$\begin{array}{c}\text { A empresa em coopera- } \\
\text { ção c/ outras empresas } \\
\text { ou institutos }\end{array}$} & \multicolumn{4}{|c|}{$\begin{array}{l}\text { Outras empresas } \\
\text { ou institutos }\end{array}$} \\
\hline & \begin{tabular}{|l|}
$1998 /$ \\
2000 \\
\end{tabular} & \begin{tabular}{|l|}
$2001 /$ \\
2003 \\
\end{tabular} & \begin{tabular}{|l|}
$2003 /$ \\
2005 \\
\end{tabular} & 2006 & \begin{tabular}{|l|}
$1998 /$ \\
2000 \\
\end{tabular} & \begin{tabular}{|l|}
$2001 /$ \\
2003 \\
\end{tabular} & $2003 /$ & \begin{tabular}{|l|}
$2006 /$ \\
2008 \\
\end{tabular} & $\begin{array}{l}1998 / \\
2000\end{array}$ & \begin{tabular}{|l|}
$2001 /$ \\
2003 \\
\end{tabular} & \begin{tabular}{|l|l|}
$2003 /$ \\
2005 \\
\end{tabular} & $\begin{array}{l}2006 / \\
2008\end{array}$ & \begin{tabular}{|l|}
$1998 /$ \\
2000 \\
\end{tabular} & \begin{tabular}{|l|}
$2001 /$ \\
2003 \\
\end{tabular} & $\begin{array}{l}2003 / \\
2005\end{array}$ & $2006 /$ \\
\hline \multicolumn{17}{|c|}{ Baixa e média-baixa intensidade tecnológica } \\
\hline Alimentos e bebidas & 19,5 & 21,6 & 15,5 & 16,0 & 3,1 & 0,6 & 0,0 & 1,1 & 29,3 & 9,9 & 10,7 & 9,9 & 48,1 & 67,9 & 73,8 & 73,0 \\
\hline Produtos têxteis & 11,6 & 18,0 & 17,3 & 24,1 & 0,0 & 0,0 & 0,0 & 0,0 & 20,9 & 18,1 & 17,3 & 16,7 & 67,4 & 63,9 & 65,4 & 59,3 \\
\hline Celulose e papel & 25,6 & 13,3 & 12,0 & 43,8 & 0,0 & 0,0 & 0,0 & 4,0 & 34,3 & 38,7 & 23,7 & 8,1 & 40,1 & 48,1 & 63,7 & 44,1 \\
\hline $\begin{array}{l}\text { Artigos } \\
\text { plástic }\end{array}$ & 7,1 & 52,2 & 36,4 & 15,2 & 0,0 & 0,0 & 0,0 & 0,0 & 29,4 & 4,3 & 0,0 & 15,2 & 23,5 & 43,5 & 63,6 & 69,7 \\
\hline Minerais não-metálicos & 32,6 & 46,2 & 35,7 & 30,0 & 0,0 & 11,5 & 0,0 & 0,0 & 16,7 & 23,1 & 21,4 & 13,3 & 50,8 & 19,2 & 42,9 & 56,7 \\
\hline Metalurgia básica & 15,7 & 13,7 & 28,6 & 13,5 & 0,0 & 4,6 & 2,9 & 0,0 & 26,2 & 13,7 & 20,0 & 10,8 & 58,0 & 68,1 & 48,6 & 75,7 \\
\hline Produtos de metal & 33,4 & 49,7 & 12,0 & 23,5 & 0,0 & 0,0 & 0,0 & 2,9 & 13,4 & 4,1 & 8,0 & 8,8 & 53,2 & 46,2 & 80,0 & 64,7 \\
\hline $\begin{array}{l}\text { Móveis e } \\
\text { diversas }\end{array}$ & 38,7 & 39,2 & 35,5 & 34,3 & 0,0 & 0,0 & 0,0 & 0,0 & 0, & 9,9 & 16,1 & 17,2 & 54,8 & 49,5 & 48,4 & 48,5 \\
\hline \multicolumn{17}{|c|}{ Alta e média-alta intensidade tecnológica } \\
\hline Produtos químicos & 42,9 & 46,5 & 55,1 & 20,8 & 0,0 & 2,6 & 4,1 & 4,2 & 35,5 & 23,8 & 14,3 & 10,4 & 21,6 & 27,1 & 26,5 & 64,6 \\
\hline $\begin{array}{l}\text { Máquinas e } \\
\text { equipamentos }\end{array}$ & 62,3 & 19,8 & 23,5 & 25,7 & 0,0 & 0,0 & 2,9 & 2,9 & 14,4 & 16,3 & 17,6 & 5,7 & 23,3 & 63,9 & 55,9 & 65,7 \\
\hline $\begin{array}{l}\text { Máqui } \\
\text { materi }\end{array}$ & 54,9 & 42,4 & 46,2 & 21,7 & 0,0 & 0,0 & 0,0 & 4,3 & 27,4 & 16,5 & 15,4 & 8,7 & 17,7 & 41,1 & 38,5 & 65,2 \\
\hline $\begin{array}{l}\text { Eletrônico e comuni- } \\
\text { cações }\end{array}$ & 22,2 & n.d. & n.d. & 22,0 & 11,1 & n.d. & n.d. & 5,8 & 0,0 & n.d. & n.d. & 22,4 & 66,7 & n.d. & n.d. & 49,8 \\
\hline $\begin{array}{l}\text { Veículos automotores, } \\
\text { reboques e carrocerias }\end{array}$ & 49,5 & 37,6 & 36,4 & 36,4 & 0,0 & 4,4 & 9,1 & 0,0 & 22,1 & 16,3 & 9,1 & 9,1 & 28,4 & 41,7 & 46,1 & 54,5 \\
\hline
\end{tabular}

Nota: n.d.= dados não disponíveis.

Fonte de dados: PINTECs 2000, 2003, 2005 e 2008 (tabulações especiais).

Para as empresas estrangeiras (Tabela 5), a responsabilidade de "outras empresas ou institutos" também ganha relevância no desenvolvimento de processos, ainda que permaneça uma melhor distribuição das responsabilidades, a exemplo do que ocorre com o desenvolvimento de produtos. À exceção da própria empresa, os responsáveis 
pelo desenvolvimento de produtos/processos (outra empresa do grupo; cooperação e outras empresas ou institutos) tanto podem estar localizados em território nacional como no exterior, o que amplia a capacidade de diversificação do desenvolvimento de inovações por parte das empresas estrangeiras. Essa situação é compatível com uma melhor distribuição das responsabilidades, se comparada às grandes empresas nacionais.

Tabela 5 - Principal responsável pelo desenvolvimento de processo nas empresas estrangeiras com 500 e mais pessoas ocupadas que implementaram inovações, por atividades selecionadas da indústria de transformação - Brasil - 1998-2008 (em \%)

\begin{tabular}{|c|c|c|c|c|c|c|c|c|c|c|c|c|c|c|c|c|}
\hline \multirow{2}{*}{$\begin{array}{l}\text { Indústria de } \\
\text { transformação } \\
\text { Atividade econômica }\end{array}$} & \multicolumn{4}{|c|}{ A empresa } & \multicolumn{4}{|c|}{ Outra empresa do grupo } & \multicolumn{4}{|c|}{$\begin{array}{c}\text { A empresa em } \\
\text { cooperação c/ outras } \\
\text { empresas ou institutos }\end{array}$} & \multicolumn{4}{|c|}{$\begin{array}{l}\text { Outras empresas ou } \\
\text { institutos }\end{array}$} \\
\hline & $\begin{array}{l}1998 / \\
2000\end{array}$ & $2001 /$ & 2003 & $2006 /$ & $\begin{array}{l}1998 / \\
2000\end{array}$ & $2001 /$ & $2003 /$ & $2006 /$ & $1998 /$ & $2001 /$ & $2003 /$ & $2006 /$ & 1998 & $2001 /$ & $2003 /$ & 2006 \\
\hline \multicolumn{17}{|c|}{ Baixa e média-baixa intensidade tecnológica } \\
\hline Alimentos e bebidas & 20,3 & 18,5 & 22,2 & 10,1 & 15,2 & 7,1 & 11,1 & 12,5 & 25,3 & 24,5 & 13,9 & 15,2 & 39,2 & 50,0 & 52,8 & 62,2 \\
\hline Produtos têxteis & 25,0 & n.d. & n.d. & 0,0 & 25,0 & n.d. & n.d. & 20,0 & 25,0 & n.d. & n.d. & 20,0 & 25,0 & n.d. & n.d. & 60,0 \\
\hline Celulos & 34,5 & n.d. & 50,0 & 17,1 & 0,0 & n.d. & 10,0 & 17,6 & 23,0 & n.d. & 0,0 & 0,0 & 42,5 & n.d. & 40,0 & 65,9 \\
\hline $\begin{array}{l}\text { Artigos de borracha e } \\
\text { plásticos }\end{array}$ & 42,9 & n.d. & 8,3 & 18,2 & 14,3 & n.d. & 33,3 & 36,4 & 14,3 & n.d. & 16,7 & 9,1 & 28,6 & n.d. & 41,7 & 36,4 \\
\hline Mine & 14,3 & n.d. & 10,0 & 8,3 & 28,6 & n.d. & 70,0 & 0,0 & 14,3 & n.d. & 0,0 & 16,7 & 42,9 & n.d. & 20,0 & 75,0 \\
\hline Meta & 58,3 & 27,0 & 22,2 & 37,5 & 8,3 & 18,0 & 22,2 & 12,5 & 16,7 & 9,0 & 11,1 & 6,3 & 16,7 & 46,0 & 44,5 & 43,8 \\
\hline Produtos de metal & 23,4 & n.d. & n.d. & 28,6 & 51,1 & n.d. & n.d. & 28,6 & 0,0 & n.d. & n.d. & 0,0 & 25,5 & n.d. & n.d. & 42,9 \\
\hline $\begin{array}{l}\text { Móveis e indústrias } \\
\text { diversas }\end{array}$ & 57,1 & n.d. & n.d. & 0,0 & 14,3 & n.d. & n.d. & 40,0 & 0,0 & n.d. & n.d. & 20,0 & 28,6 & n.d. & n.d. & 40,0 \\
\hline \multicolumn{17}{|c|}{ Alta e média-alta intensidade tecnológica } \\
\hline Produtos químicos & 46,8 & 27,3 & 25,6 & 20,5 & 9,0 & 24,4 & 17,9 & 23,1 & 20,9 & 24,4 & 20,5 & 10,3 & 23,3 & 23,9 & 35,9 & 46,2 \\
\hline $\begin{array}{l}\text { Máquinas e } \\
\text { equipamentos }\end{array}$ & 34,6 & 26,3 & 22,2 & 23,1 & 15,4 & 11,8 & 14,8 & 3,8 & 26,9 & 23,6 & 29,6 & 7,7 & 23,1 & 38,2 & 33,4 & 65,4 \\
\hline $\begin{array}{l}\text { Máquinas, aparelhos e } \\
\text { materiais elétricos }\end{array}$ & 23,9 & 26,8 & 45,0 & 31,6 & 28,7 & 13,4 & 15,0 & 26,3 & 14,0 & 19,8 & 20,0 & 0,0 & 33,4 & 40,0 & 20,0 & 42,1 \\
\hline $\begin{array}{l}\text { Eletrônico e } \\
\text { comunicações }\end{array}$ & 28,1 & 13,9 & 8,3 & 24,4 & 16,4 & 32,2 & 33,3 & 29,9 & 10,9 & 46,4 & 33,3 & 13,1 & 44,5 & 7,5 & 25,0 & 32,6 \\
\hline $\begin{array}{l}\text { Veículos automotores, } \\
\text { reboques e carrocerias }\end{array}$ & 25,0 & 12,7 & 25,4 & 32,1 & 17,8 & 22,7 & 20,2 & 20,8 & 30,7 & 33,7 & 25,7 & 9,4 & 14,2 & 30,9 & 29,9 & 37,7 \\
\hline
\end{tabular}

Nota: n.d. $=$ dados não disponíveis.

Fonte de dados: PINTECs 2000, 2003, 2005 e 2008 (tabulações especiais).

Quanto mais concentrada na empresa a responsabilidade pelo desenvolvimento de produtos/processos, menores são as possibilidades de difusão do conhecimento, a partir do processo de aprendizado 
interativo. Nesse sentido, tanto as empresas nacionais quanto as estrangeiras são mais propensas a compartilhar o desenvolvimento de processos do que de produtos. Para as empresas estrangeiras, a responsabilidade de "outras empresas ou institutos" também possui relevância no desenvolvimento de processos, ainda que haja uma distribuição de responsabilidades mais homogênea, se comparada com as empresas nacionais, a exemplo do que ocorre com o desenvolvimento de produtos.

\subsection{Fontes de informação e sua localização}

Conjuntamente, as fontes de informação ${ }^{8}$ e as relações de cooperação refletem a interação dos diferentes atores que formam um SNI. Por conseguinte, refletem também a dimensão em que se dá a difusão do conhecimento e o aprofundamento do processo de aprendizado interativo, nas diferentes atividades econômicas (Lundvall, 2007).

Considera-se apenas o nível de importância mais elevado ("alta") que as empresas inovadoras apontaram para cada categoria de "fonte externa de informação," " tendo em vista que é nesse nível que essas "fontes" melhor definem a estratégia de inovação adotada pelas empresas. Em se tratando das grandes empresas nacionais (Tabela 6), destacam-se, como fontes externas de informação, os "fornecedores", tanto com localização em território nacional como no exterior e "clientes ou consumidores", com predomínio da localização em território nacional. Com um pouco menos de importância aparecem os "concorrentes", também com localização em território nacional.

8 Conforme o IBGE (2007, p. 49): "As fontes de informação que a empresa pode utilizar são variadas e a escolha destas fontes irá depender da estratégia de inovação implementada e da capacidade das empresas de absorver e combinar tais informações." Neste sentido, ressaltase a importância do "movimento espiral" do conhecimento (Lundvall, 1996), em que os componentes tácito e codificado se afetam mutuamente.

9 As fontes internas são: departamento de P\&D e "outras áreas" da própria empresa. Como o objetivo central, nesse caso, é verificar a interação da empresa com o ambiente, serão consideradas apenas as principais fontes externas de informação. 
Tabela 6 - Empresas nacionais, com 500 e mais pessoas ocupadas, que implementaram inovações, por grau de importância (alta) das fontes externas de informação empregadas, segundo atividades selecionadas da indústria de transformação - Brasil- 1998-2008 (em \%)

\begin{tabular}{|c|c|c|c|c|c|c|c|c|c|c|c|c|c|c|c|c|}
\hline \multirow{2}{*}{$\begin{array}{l}\text { Indústria de } \\
\text { transformação } \\
\text { Atividade } \\
\text { econômica }\end{array}$} & \multicolumn{4}{|c|}{ Outra empresa do grupo } & \multicolumn{4}{|c|}{ Fornecedores } & \multicolumn{4}{|c|}{$\begin{array}{l}\text { Clientes ou } \\
\text { consumidores }\end{array}$} & \multicolumn{4}{|c|}{ Concorrentes } \\
\hline & \begin{tabular}{|l|}
$1998 /$ \\
2000 \\
\end{tabular} & \begin{tabular}{|l|}
$2001 /$ \\
2003 \\
\end{tabular} & \begin{tabular}{|l|}
$2003 /$ \\
2005 \\
\end{tabular} & \begin{tabular}{|l|}
$2006 /$ \\
2008 \\
\end{tabular} & \begin{tabular}{|l|}
$1998 /$ \\
2000 \\
\end{tabular} & \begin{tabular}{|l|}
$2001 /$ \\
2003 \\
\end{tabular} & \begin{tabular}{|l|}
$2003 /$ \\
2005 \\
\end{tabular} & \begin{tabular}{|l|}
$2006 /$ \\
2008 \\
\end{tabular} & \begin{tabular}{|l|}
$1998 /$ \\
2000 \\
\end{tabular} & \begin{tabular}{|l|}
$2001 /$ \\
2003 \\
\end{tabular} & \begin{tabular}{|l|}
$2003 /$ \\
2005 \\
\end{tabular} & \begin{tabular}{|l|}
$2006 /$ \\
2008 \\
\end{tabular} & \begin{tabular}{|l|}
$1998 /$ \\
2000 \\
\end{tabular} & \begin{tabular}{|l|}
$2001 /$ \\
2003 \\
\end{tabular} & \begin{tabular}{|l|}
$2003 /$ \\
2005 \\
\end{tabular} & $\begin{array}{l}2006 / \\
2008 \\
\end{array}$ \\
\hline \multicolumn{17}{|c|}{ Baixa e média-baixa intensidade tecnológica } \\
\hline $\begin{array}{l}\text { Alimentos e } \\
\text { bebidas }\end{array}$ & 9,8 & 6,7 & 7,3 & 12,5 & 47,8 & 43,3 & 50,4 & 52,3 & 39,1 & 33,7 & 41,8 & 36,0 & 22,7 & 20,3 & 25,0 & 22,2 \\
\hline Produtos têxteis & 6,4 & 2,1 & 3,4 & 6,6 & 57,4 & 44,2 & 48,3 & 49,2 & 48,9 & 37,4 & 50,0 & 44,0 & 21,3 & 18,9 & 27,6 & 27,9 \\
\hline Celulose e papel & 4,8 & 15,7 & 11,2 & 13,2 & 57,1 & 56,4 & 59,3 & 53,5 & 57,4 & 55,8 & 44,4 & 37,0 & 28,9 & 28,4 & 18,4 & 13,4 \\
\hline $\begin{array}{l}\text { Artigos de borra- } \\
\text { cha e plásticos }\end{array}$ & 14,3 & 11,5 & 7,1 & 5,7 & 47,6 & 42,3 & 38,1 & 48,6 & 57,1 & 76,9 & 54,8 & 83,0 & 9,5 & 23,1 & 21,4 & 14,3 \\
\hline $\begin{array}{l}\text { Minerais } \\
\text { não-metálicos }\end{array}$ & 15,8 & 6,7 & 15,2 & 20,6 & 36,8 & 33,3 & 45,5 & 47,1 & 47,3 & 53,3 & 45,5 & 65,0 & 31,6 & 33,3 & 33,3 & 26,5 \\
\hline $\begin{array}{l}\text { Metalurgia } \\
\text { básica }\end{array}$ & 14,2 & 21,8 & 13,5 & 17,5 & 57,0 & 43,5 & 37,8 & 45,0 & 33,2 & 34,8 & 48,6 & 45,0 & 19,0 & 13,1 & 16,2 & 22,5 \\
\hline $\begin{array}{l}\text { Produtos de } \\
\text { metal }\end{array}$ & 12,1 & 3,7 & 3,4 & 8,6 & 39,1 & 33,1 & 48,3 & 45,7 & 45,6 & 41,1 & 55,2 & 57,0 & 9,1 & 14,7 & 24,1 & 31,4 \\
\hline $\begin{array}{l}\text { Móveis e indús- } \\
\text { trias diversas }\end{array}$ & 7,2 & 0,0 & 5,7 & 14,2 & 50,7 & 24,3 & 40,0 & 54,1 & 43,2 & 51,1 & 54,3 & 63,0 & 31,6 & 30,5 & 34,3 & 11,5 \\
\hline \multicolumn{17}{|c|}{ Alta e média-alta intensidade tecnológica } \\
\hline $\begin{array}{l}\text { Produtos } \\
\text { químicos }\end{array}$ & 4,8 & 10,1 & 12,5 & 11,3 & 38,5 & 45,5 & 41,1 & 28,3 & 33,6 & 53,5 & 55,4 & 43,0 & 26,4 & 33,1 & 39,3 & 20,8 \\
\hline $\begin{array}{l}\text { Máquinas e } \\
\text { equipamentos }\end{array}$ & 0,0 & 14,3 & 6,8 & 14,6 & 32,2 & 41,9 & 50,0 & 36,6 & 41,3 & 39,0 & 63,6 & 61,0 & 10,9 & 28,9 & 27,3 & 14,6 \\
\hline $\begin{array}{l}\text { Máquinas, } \\
\text { aparelhos e ma- } \\
\text { teriais elétricos }\end{array}$ & 0,0 & 11,3 & 0,0 & 4,3 & & 47,3 & 31,2 & 56,5 & 58,7 & 39,8 & 37,5 & 22,0 & 50,3 & 34,4 & 25,0 & 30,4 \\
\hline $\begin{array}{l}\text { Eletrônico e } \\
\text { comunicações }\end{array}$ & 14,3 & n.d. & n.d. & 15,3 & 28,6 & n.d. & n.d. & 30,0 & 57,1 & n.d. & n.d. & 55,0 & 14,3 & n.d. & n.d. & 25,1 \\
\hline $\begin{array}{l}\text { Veículos } \\
\text { automotores, } \\
\text { reboques e } \\
\text { carrocerias }\end{array}$ & 6,8 & 11,3 & 11,0 & 8,9 & 61,8 & 36,7 & 52,7 & 35,6 & 56,0 & 66,5 & 67,1 & 78,0 & 37,9 & 18,4 & 28,0 & 15,6 \\
\hline
\end{tabular}

Nota: n.d. $=$ dados não disponíveis.

Fonte de dados: PINTECs 2000, 2003, 2005 e 2008 (tabulações especiais).

Para as grandes empresas estrangeiras inovadoras, segundo as atividades econômicas consideradas (Tabela 7), o destaque como "fonte externa de informação" fica por conta de "outra empresa do grupo", corroborando, mais uma vez, a ênfase que estas empresas dedicam às estratégias intra-corporativas em sua trajetória de inovação. Neste caso, é importante ressaltar que o exterior foi a localização preponderante das "fontes de informação empregadas" para todas as atividades e em todo o período considerado. 
Tabela 7 - Empresas estrangeiras, com 500 e mais pessoas ocupadas, que implementaram inovações, por grau de importância (alta) das fontes externas de informação empregadas, segundo atividades selecionadas da indústria de transformação - Brasil- 1998-2008 (em \%)

\begin{tabular}{|c|c|c|c|c|c|c|c|c|c|c|c|c|c|c|c|c|}
\hline \multirow{2}{*}{$\begin{array}{l}\text { Indústria de } \\
\text { transformação } \\
\text { Atividade } \\
\text { econômica }\end{array}$} & \multicolumn{4}{|c|}{$\begin{array}{c}\text { Outra empresa } \\
\text { do grupo }\end{array}$} & \multicolumn{4}{|c|}{ Fornecedores } & \multicolumn{4}{|c|}{$\begin{array}{l}\text { Clientes ou } \\
\text { consumidores }\end{array}$} & \multicolumn{4}{|c|}{ Concorrentes } \\
\hline & \begin{tabular}{|l|}
$1998 /$ \\
2000 \\
\end{tabular} & \begin{tabular}{|l}
$2001 /$ \\
2003 \\
\end{tabular} & \begin{tabular}{|l|}
$2003 /$ \\
2005 \\
\end{tabular} & \begin{tabular}{|l|}
$2006 /$ \\
2008 \\
\end{tabular} & \begin{tabular}{|l|}
$1998 /$ \\
2000 \\
\end{tabular} & \begin{tabular}{|l|}
$2001 /$ \\
2003
\end{tabular} & \begin{tabular}{|l|}
$2003 /$ \\
2005 \\
\end{tabular} & \begin{tabular}{|l|}
$2006 /$ \\
2008 \\
\end{tabular} & \begin{tabular}{|l|}
$1998 /$ \\
2000 \\
\end{tabular} & \begin{tabular}{|l|}
$2001 /$ \\
2003 \\
\end{tabular} & \begin{tabular}{|l}
$2003 /$ \\
2005 \\
\end{tabular} & \begin{tabular}{|l|}
$2006 /$ \\
2008 \\
\end{tabular} & \begin{tabular}{|l|}
$1998 /$ \\
2000 \\
\end{tabular} & \begin{tabular}{|l}
$2001 /$ \\
2003 \\
\end{tabular} & \begin{tabular}{|l|}
$2003 /$ \\
2005
\end{tabular} & \begin{tabular}{|l|}
$2006 /$ \\
2008 \\
\end{tabular} \\
\hline \multicolumn{17}{|c|}{ Baixa e média-baixa intensidade tecnológica } \\
\hline $\begin{array}{l}\text { Alimentos e } \\
\text { bebidas }\end{array}$ & 44,8 & 40,9 & 51,2 & 69,0 & 58,6 & 36,5 & 34,1 & 44,4 & 54,6 & 47,1 & 43,9 & 64,3 & 31,6 & 18,4 & 22,0 & 28,8 \\
\hline Produtos têxteis & 60,0 & n.d. & n.d. & 57,1 & 40,0 & n.d. & n.d. & 42,9 & 20,0 & n.d. & n.d. & 42,9 & 0,0 & n.d. & n.d. & 0,0 \\
\hline Celulose e papel & 60,3 & n.d. & 41,9 & 25,5 & 58,8 & n.d. & 16,8 & 24,5 & 51,5 & n.d. & 50,3 & 50,0 & 0,0 & n.d. & 8,4 & 12,7 \\
\hline $\begin{array}{l}\text { Artigos de borra- } \\
\text { cha e plásticos }\end{array}$ & 62,5 & n.d. & 61,5 & 43,8 & 12,5 & n.d. & 46,2 & 50,0 & 62,5 & n.d. & 53,8 & 50,0 & 37,5 & n.d. & 15,4 & 12,5 \\
\hline $\begin{array}{l}\text { Minerais não- } \\
\text {-metálicos }\end{array}$ & 85,7 & n.d. & 66,7 & 46,2 & 42,9 & n.d. & 8,3 & 46,2 & 28,6 & n.d. & 41,7 & 30,8 & 0,0 & n.d. & 16,7 & 15,4 \\
\hline Metalurgia básica & 53,8 & 39,0 & 63,6 & 37,5 & 38,5 & 23,7 & 36,4 & 37,5 & 38,5 & 46,6 & 45,5 & 62,5 & 15,4 & 23,7 & 18,2 & 25,0 \\
\hline $\begin{array}{l}\text { Produtos de } \\
\text { metal }\end{array}$ & 20,3 & n.d. & n.d. & 100,0 & 40,7 & n.d. & n.d. & 66,7 & 59,3 & n.d. & n.d. & 66,7 & 20,3 & n.d. & n.d. & 11,1 \\
\hline $\begin{array}{l}\text { Móveis e indús- } \\
\text { trias diversas }\end{array}$ & 0,0 & n.d. & n.d. & 60,0 & 32,2 & n.d. & n.d. & 40,0 & 66,6 & n.d. & n.d. & 60,0 & 0,0 & n.d. & n.d. & 40,0 \\
\hline \multicolumn{17}{|c|}{ Alta e média-alta intensidade tecnológica } \\
\hline $\begin{array}{l}\text { Produtos } \\
\text { químicos }\end{array}$ & 56,1 & 63,3 & 64,6 & 69,6 & 36,0 & 23,9 & 31,2 & 37,0 & 51,6 & 41,9 & 43,8 & 34,8 & 30,9 & 5,0 & 18,8 & 8,7 \\
\hline $\begin{array}{l}\text { Máquinas e } \\
\text { equipamentos } \\
\text { Máquinas, apare- }\end{array}$ & 43,3 & 58,2 & 53,8 & 54,8 & 26,7 & 38,5 & 48,7 & 22,6 & 60,0 & 52,7 & 64,1 & 51,6 & 20,0 & 30,5 & 12,8 & 19,4 \\
\hline $\begin{array}{l}\text { Ihos e materiais } \\
\text { elétricos }\end{array}$ & 81,8 & 64,8 & 58,3 & 62,5 & 36,2 & 41,4 & 41,7 & 29,2 & 31,9 & 35,5 & 45,8 & 37,5 & 0,0 & 11,9 & 29,2 & 8,3 \\
\hline $\begin{array}{l}\text { Eletrônico e } \\
\text { comunicações }\end{array}$ & 62,2 & 79,0 & 64,3 & 50,3 & 41,4 & 50,3 & 50,0 & 38,0 & 62,9 & 79,0 & 57,1 & 65,8 & 20,7 & 29,2 & 14,3 & 19,8 \\
\hline $\begin{array}{l}\text { Veículos automo- } \\
\text { tores, reboques e } \\
\text { carrocerias }\end{array}$ & 69,1 & 70,2 & 59,1 & 64,4 & 62,3 & 49,5 & 55,3 & 57,6 & 63,8 & 58,8 & 61,6 & 62,7 & 31,8 & 19,0 & 33,7 & 23,7 \\
\hline
\end{tabular}

Nota: n.d. = dados não disponíveis.

Fonte de dados: PINTECs 2000, 2003, 2005 e 2008 (tabulações especiais).

Outras fontes externas importantes para as empresas estrangeiras foram "fornecedores" e "clientes ou consumidores", com destaque para as atividades de fabricação de máquinas e equipamentos, material eletrônico e aparelhos de comunicação, e veículos automotores, reboques e carrocerias. A maior parte dos "fornecedores", como fonte externa de informação empregada, com poucas exceções, estava localizada no exterior.

Por sua vez, "clientes ou consumidores", como "fontes de informação empregada", localizavam-se, sem exceção no período considerado, predominantemente em território nacional. Neste sentido, evidencia- 
se que as relações dentro da cadeia (fornecedores e clientes), estão associadas, simultaneamente, às estratégias de fornecimento global e de busca de mercado. Comparando com as empresas estrangeiras, "concorrentes" têm maior importância relativa, em regra, como fontes externas de informação para as empresas nacionais, corroborando a importância das "estratégias seguidoras", seja com base no mercado nacional ou a partir do contexto internacional (caso das estrangeiras).

Em suma, em relação às fontes externas de informação, a condição de estrangeiras se apresenta como favorável ao estabelecimento de relações com o exterior ("outra empresa do grupo") para o desenvolvimento de inovações, ao passo que as grandes empresas nacionais, como esperado, tendem a concentrar suas relações no território nacional.

\subsection{Relações de cooperação}

A exemplo das taxas de inovação, as relações de cooperação também aumentam com o crescimento (faixa de pessoal ocupado) das empresas, ${ }^{10}$ o que é compatível com a elevação da escala de atividade e o aprofundamento do grau de elaboração dos produtos/processos desenvolvidos, à medida que as empresas aumentam de tamanho. Em se tratando das grandes empresas nacionais (Tabela 8), "fornecedores" e "clientes ou consumidores", destacam-se como "organizações" importantes para a "cooperação", a exemplo do que ocorre com as "fontes externas de informação".

\footnotetext{
${ }^{10}$ Para o conjunto da indústria de transformação, a participação das empresas com relações de cooperação com outras organizações no total das empresas que implementaram inovações aumentou de 3,8\% em 2001-2003 para 7,2\% em 2003-2005 e para 10,4\% em 2006-2008. Para as grandes empresas foi de $40,3 \%$ para $39,1 \%$ e para $36,73 \%$, respectivamente. (com base em dados das PINTECs)
} 
Tabela 8 - Empresas nacionais, com 500 e mais pessoas ocupadas, que implementaram inovações, com relação de cooperação com outras organizações, por grau de importância (alta) da parceria, segundo atividades selecionadas da indústria de transformação - Brasil- 1998-2008 (em \%)

\begin{tabular}{|c|c|c|c|c|c|c|c|c|c|c|c|c|c|c|c|c|}
\hline \multirow{2}{*}{$\begin{array}{l}\text { Indústria de } \\
\text { transformação } \\
\text { Atividade econômica }\end{array}$} & \multicolumn{4}{|c|}{$\begin{array}{l}\text { Outra empresa } \\
\text { do grupo }\end{array}$} & \multicolumn{4}{|c|}{ Fornecedores } & \multicolumn{4}{|c|}{$\begin{array}{l}\text { Clientes ou } \\
\text { consumidores }\end{array}$} & \multicolumn{4}{|c|}{ Concorrentes } \\
\hline & \begin{tabular}{|l|}
$1998 /$ \\
2000 \\
\end{tabular} & $\begin{array}{l}2001 / \\
2003\end{array}$ & \begin{tabular}{|l|}
$2003 /$ \\
2005 \\
\end{tabular} & $\begin{array}{l}2006 / \\
2008\end{array}$ & $\begin{array}{l}1998 / \\
2000\end{array}$ & \begin{tabular}{|l|}
$2001 /$ \\
2003
\end{tabular} & \begin{tabular}{|l|}
$2003 /$ \\
2005 \\
\end{tabular} & \begin{tabular}{|l|}
$2006 /$ \\
2008 \\
\end{tabular} & \begin{tabular}{|l|}
$1998 /$ \\
2000 \\
\end{tabular} & $2001 /$ & \begin{tabular}{|l|}
$2003 /$ \\
2005
\end{tabular} & $2006 /$ & $\begin{array}{l}1998 / \\
2000 \\
\end{array}$ & \begin{tabular}{|l|}
$2001 /$ \\
2003 \\
\end{tabular} & $\begin{array}{l}2003 / \\
2005 \\
\end{array}$ & $2006 /$ \\
\hline \multicolumn{17}{|c|}{ Baixa e média-baixa intensidade tecnológica } \\
\hline Alimentos e bebidas & 0,8 & 1,3 & 1,3 & 3,0 & 17,8 & 8,5 & 12,1 & 15,3 & 8,6 & 3,1 & 4,7 & 7,9 & 3,1 & 0,5 & 2,6 & 3,9 \\
\hline Produtos têxteis & 2,1 & 6,2 & 0,0 & 1,6 & 14,9 & 22,8 & 15,5 & 13,1 & 8,5 & 16,4 & 8,6 & 8,2 & 0,0 & 0,0 & 0,0 & 1,6 \\
\hline Celulose e papel & 0,0 & 11,7 & 0,0 & 6,5 & 22,7 & 23,9 & 25,8 & 23,3 & 8,9 & 27,4 & 14,6 & 13,4 & 0,0 & 0,0 & 0,0 & 3,4 \\
\hline $\begin{array}{l}\text { Artigos de borracha } \\
\text { e plásticos }\end{array}$ & 0,0 & 3,8 & 2,4 & 5,7 & 14,3 & 11,5 & 9,5 & 22,9 & 14,3 & 19,2 & 14,3 & 25,7 & 9,5 & 0,0 & 0,0 & 2,9 \\
\hline $\begin{array}{l}\text { Minerais não- } \\
\text {-metálicos }\end{array}$ & 5,3 & 10,0 & 12,1 & 11,8 & 31,6 & 40,0 & 24,2 & 23,5 & 10,5 & 26,7 & 18,2 & 26,5 & 0,0 & 6,7 & 0,0 & 0,0 \\
\hline Metalurgia básica & 14,2 & 8,7 & 2,7 & 5,0 & 14,2 & 8,7 & 32,4 & 12,5 & 28,5 & 26,0 & 18,9 & 32,5 & 4,7 & 0,0 & 0,0 & 7,5 \\
\hline rodutos de metal & 3,0 & 3,7 & 3,4 & 5,7 & 6,1 & 22,1 & 13,8 & 11,4 & 11,8 & 11,0 & 13,8 & 20,0 & 0,0 & 0,0 & 3,4 & 2,9 \\
\hline $\begin{array}{l}\text { Móveis e indústrias } \\
\text { diversas }\end{array}$ & 3,6 & 0,0 & 2,9 & 5,6 & 21,3 & 3,0 & 8,6 & 22,7 & 18,0 & 15,4 & 14,3 & 11,4 & 7,0 & 0,0 & 2,9 & 2,8 \\
\hline \multicolumn{17}{|c|}{ Alta e média-alta intensidade tecnológica } \\
\hline Produtos químicos & 2,5 & 10,1 & 5,4 & 7,5 & 11,5 & 22,0 & 28,6 & 17,0 & 9,5 & 20,1 & 25,0 & 13,2 & 0,0 & 5,9 & 7,1 & 3,8 \\
\hline $\begin{array}{l}\text { Máquinas e equipa- } \\
\text { mentos }\end{array}$ & 0,0 & 8,5 & 4,5 & 4,9 & 3,6 & 17,8 & 13,6 & 7,3 & 3,6 & 14,9 & 18,2 & 14,6 & 0,0 & 0,0 & 0,0 & 4,9 \\
\hline $\begin{array}{l}\text { Máquinas, aparelhos } \\
\text { e materiais elétricos }\end{array}$ & 0,0 & 0,0 & 0,0 & 4,3 & 8,4 & 22,8 & 18,7 & 17,4 & 16,8 & 5,6 & 25,0 & 4,3 & 0,0 & 5,6 & 6,3 & 0,0 \\
\hline $\begin{array}{l}\text { Eletrônico e comuni- } \\
\text { cações }\end{array}$ & 7,1 & n.d. & n.d. & 15,3 & 14,3 & n.d. & n.d. & 40,1 & 14,3 & n.d. & n.d. & 19,9 & 0,0 & n.d. & n.d. & 0,0 \\
\hline $\begin{array}{l}\text { Veículos automo- } \\
\text { tores, reboques e } \\
\text { carrocerias }\end{array}$ & 6,6 & 22,5 & 11,0 & 8,9 & 17,8 & 33,7 & 38,4 & 35,6 & 34,9 & 29,5 & 32,9 & 28,9 & 0,0 & 3,9 & 2,7 & 0,0 \\
\hline
\end{tabular}

Nota: n.d. $=$ dados não disponíveis.

Fonte de dados: PINTECs 2000, 2003, 2005 e 2008 (tabulações especiais)

Seguindo a tendência do que ocorre com as "fontes externas de inovação", a proporção de grandes empresas estrangeiras que consideram "alta" a importância da "parceria", no que se refere às "relações de cooperação com outras organizações", é significativo o papel de "outra empresa do grupo" entre as empresas que inovaram e mantinham relações de cooperação, para a grande maioria das atividades econômicas consideradas (Tabela 9). 
Tabela 9 - Empresas estrangeiras, com 500 e mais pessoas ocupadas, que implementaram inovações, com relações de cooperação com outras organizações, por grau de importância (alta) da parceria, segundo atividades selecionadas da indústria de transformação - Brasil- 1998-2008 (em \%)

\begin{tabular}{|c|c|c|c|c|c|c|c|c|c|c|c|c|c|c|c|c|}
\hline \multirow{2}{*}{$\begin{array}{l}\text { Indústria de } \\
\text { transformação } \\
\text { Atividade } \\
\text { econômica }\end{array}$} & \multicolumn{4}{|c|}{$\begin{array}{c}\text { Outra empresa } \\
\text { do grupo }\end{array}$} & \multicolumn{4}{|c|}{ Fornecedores } & \multicolumn{4}{|c|}{$\begin{array}{l}\text { Clientes ou } \\
\text { consumidores }\end{array}$} & \multicolumn{4}{|c|}{ Concorrentes } \\
\hline & \begin{tabular}{|l|}
$1998 /$ \\
2000 \\
\end{tabular} & \begin{tabular}{|l|}
$2001 /$ \\
2003 \\
\end{tabular} & \begin{tabular}{|l|}
$2003 /$ \\
2005 \\
\end{tabular} & \begin{tabular}{|l|}
$2006 /$ \\
2008 \\
\end{tabular} & \begin{tabular}{|l|}
$1998 /$ \\
2000 \\
\end{tabular} & \begin{tabular}{|l|}
$2001 /$ \\
2003 \\
\end{tabular} & \begin{tabular}{|l|}
$2003 /$ \\
2005 \\
\end{tabular} & \begin{tabular}{|l|}
$2006 /$ \\
2008 \\
\end{tabular} & \begin{tabular}{|l|}
$1998 /$ \\
2000 \\
\end{tabular} & \begin{tabular}{|l|}
$2001 /$ \\
2003 \\
\end{tabular} & \begin{tabular}{|l}
$2003 /$ \\
2005 \\
\end{tabular} & $\begin{array}{l}2006 / \\
2008 \\
\end{array}$ & \begin{tabular}{|l|}
$1998 /$ \\
2000 \\
\end{tabular} & $\begin{array}{l}2001 / \\
2003 \\
\end{array}$ & \begin{tabular}{|l|}
$2003 /$ \\
2005 \\
\end{tabular} & \begin{tabular}{|l|}
$2006 /$ \\
2008 \\
\end{tabular} \\
\hline \multicolumn{17}{|c|}{ Baixa e média-baixa intensidade tecnológica } \\
\hline $\begin{array}{l}\text { Alimentos } \\
\text { e bebidas }\end{array}$ & 13,8 & 30,9 & 39,0 & 22,5 & 18,4 & 24,9 & 17,1 & 22,3 & 4,6 & 18,7 & 19,5 & 13,3 & 0,0 & 0,0 & 4,9 & 6,6 \\
\hline Produtos têxteis & 0,0 & n.d. & n.d. & 14,3 & 0,0 & n.d. & n.d. & 28,6 & 20,0 & n.d. & n.d. & 28,6 & 0,0 & n.d. & n.d. & 0,0 \\
\hline $\begin{array}{l}\text { Celulose } \\
\text { e papel }\end{array}$ & 41,2 & n.d. & 16,8 & 12,7 & 20,6 & n.d. & 16,8 & 37,3 & 20,6 & n.d. & 16,8 & 25,5 & 0,0 & n.d. & 0,0 & 0,0 \\
\hline $\begin{array}{l}\text { Artigos de borra- } \\
\text { cha e plásticos }\end{array}$ & 50,0 & n.d. & 38,5 & 18,8 & 25,0 & n.d. & 46,2 & 12,5 & 62,5 & n.d. & 30,8 & 18,8 & 0,1 & n.d. & 7,7 & 6,3 \\
\hline $\begin{array}{l}\text { Minerais } \\
\text { não-metálicos }\end{array}$ & 42,9 & n.d. & 50,0 & 15,4 & 14,3 & n.d. & 25,0 & 30,8 & 14,3 & n.d. & 33,3 & 30,8 & 0,0 & n.d. & 0,0 & 0,0 \\
\hline $\begin{array}{l}\text { Metalurgia } \\
\text { básica }\end{array}$ & 38,5 & 39,0 & 27,3 & 31,3 & 15,4 & 16,1 & 18,2 & 12,5 & 23,1 & 39,0 & 45,5 & 37,5 & 0,0 & 0,0 & 0,0 & 0,0 \\
\hline $\begin{array}{l}\text { Produtos de } \\
\text { metal }\end{array}$ & 0,0 & n.d. & n.d. & 55,6 & 18,6 & n.d. & n.d. & 22,2 & 0,0 & n.d. & n.d. & 33,3 & 0,0 & n.d. & n.d. & 0,0 \\
\hline $\begin{array}{l}\text { Móveis e indús- } \\
\text { trias diversas }\end{array}$ & 0,0 & n.d. & n.d. & 40,0 & 14,6 & n.d. & n.d. & 20,0 & 14,6 & n.d. & n.d. & 20,0 & 0,0 & n.d. & n.d. & 20,0 \\
\hline \multicolumn{17}{|c|}{ Alta e média-alta intensidade tecnológica } \\
\hline $\begin{array}{l}\text { Produtos } \\
\text { químicos }\end{array}$ & 31,6 & 29,3 & 39,6 & 34,8 & 8,4 & 19,7 & 14,6 & 26,1 & 16,2 & 24,6 & 12,5 & 15,2 & 0,0 & 0,0 & 2,1 & 2,2 \\
\hline $\begin{array}{l}\text { Máquinas e } \\
\text { equipamentos }\end{array}$ & 23,3 & 36,1 & 30,8 & 48,4 & 16,7 & 27,6 & 15,4 & 12,9 & 23,3 & 21,8 & 15,4 & 16,1 & 0,0 & 0,0 & 0,0 & 0,0 \\
\hline $\begin{array}{l}\text { Máquinas, } \\
\text { aparelhos e ma- } \\
\text { teriais elétricos }\end{array}$ & 27,4 & 35,5 & 20,8 & 29,2 & 9,1 & 5,9 & 16,7 & 8,3 & 22,8 & 11,8 & 20,8 & 16,7 & 0,0 & 0,0 & 0,0 & 0,0 \\
\hline $\begin{array}{l}\text { Eletrônico e } \\
\text { comunicações }\end{array}$ & 31,9 & 46,6 & 35,7 & 23,8 & 25,9 & 29,2 & 21,4 & 11,8 & 36,3 & 32,0 & 21,4 & 19,5 & 0,0 & 0,1 & 0,0 & 4,0 \\
\hline $\begin{array}{l}\text { Veículos automo- } \\
\text { tores, reboques e } \\
\text { carrocerias }\end{array}$ & 48,2 & 40,1 & 40,6 & 33,9 & 24,4 & 33,5 & 31,8 & 33,9 & 27,3 & 35,2 & 20,4 & 25,4 & 0,1 & 0,0 & 2,5 & 0,0 \\
\hline
\end{tabular}

Nota: n.d. $=$ dados não disponíveis.

Fonte de dados: PINTECs 2000, 2003, 2005 e 2008 (tabulações especiais).

"Fornecedores" e "clientes ou consumidores" também se apresentam como importantes "parceiros", na cooperação para a inovação, entre as empresas estrangeiras. Por sua vez, os "concorrentes" não possuem um elevado nível de importância como "parceiros", em nenhuma das atividades consideradas, a exemplo do que ocorre com as grandes empresas nacionais. Para as grandes empresas estrangeiras da indústria de transformação brasileira os "fornecedores", apesar de terem sido considerados importantes "parceiros", ficam atrás de "outra empresa do grupo" e de "clientes ou consumidores", no que se refere às relações de cooperação nas empresas que implementaram inovações entre 1998-2008. No caso das grandes empresas nacionais, 
os "fornecedores", com poucas exceções, têm sido considerados os "parceiros" mais importantes na cooperação para a inovação. Tanto para empresas nacionais como para estrangeiras, a localização (Brasil ou exterior) dos "parceiros" segue a mesma tendência da localização das "fontes externas de informação"; ou seja, há um predomínio da localização dos parceiros das grandes empresas nacionais em território nacional, e um predomínio da "parceria" com organizações localizadas no exterior no caso das grandes empresas estrangeiras.

Em linhas gerais, comparando-se grandes empresas da indústria de transformação brasileira, por origem de capital, verifica-se que, para as estrangeiras, há uma maior dependência das "estruturas organizacionais hierarquicamente integradas" (governança corporativa) (Williamson, 1989), no que diz respeito à cooperação, como forma de promover atividades inovativas, inclusive no que se refere à "parceria" com outras organizações localizadas no exterior.

No caso das grandes empresas nacionais, a ênfase na cooperação com fornecedores revela a maior necessidade de desenvolvimento de inovações na cadeia produtiva, com empresas localizadas em território nacional. Isso demonstra um comportamento relativamente favorável ao desenvolvimento de capacitações em território nacional, por parte das grandes empresas nacionais.

No que se refere à cooperação, a diversidade das atividades da indústria de transformação brasileira tem servido mais às ações inovativas das grandes empresas nacionais do que das estrangeiras. Ou seja, tanto no que diz respeito ao sentido horizontal (concorrência) como ao vertical (cadeia produtiva) da cooperação, as empresas nacionais têm desenvolvido atividades de forma mais integrada, em relações de "parceria" com outras organizações em território nacional.

\subsection{Qualificação da ocupação, esforço inovativo e importância da P\&D}

A maior integração vertical da empresa exige também uma verticalização da organização do trabalho, à medida que aumenta a exigência das qualificações necessárias dos trabalhadores (educação e treinamento) para o desenvolvimento do processo de aprendizado 
organizacional (interno e interativo) relativo à inovação. Nesse sentido, as grandes empresas, em regra, tendem a concentrar um maior contingente de pessoas qualificadas em atividades de $P \& D$, se comparadas às empresas de menor porte, como tem sido demonstrado pelas PINTECs (2000, 2003, 2005 e 2008).

O enfoque aqui adotado está centrado nos efeitos sobre o aprendizado, a partir da importância das grandes empresas e das suas relações de cooperação/mercado, necessárias para a transferência/criação de conhecimento tácito e codificado, ou seja, da importância deste processo para a inovação, considerando-se especificamente as atividades de $\mathrm{P} \& \mathrm{D}$, como fontes fundamentais de geração de inovações.

Existe uma relação entre rotina, processo de aprendizado e conhecimento tácito, em que a inovação (processo criativo) é resultado da relação entre compreensão e execução, que conduzem a uma melhor concepção do processo produtivo e/ou organizacional; daí a importância dos indivíduos para as organizações. É neste sentido que a qualificação das pessoas ocupadas em $P \& D$ se constitui em um importante indicador da relação entre processo de aprendizado e inovação.

O processo de aprendizado pode ser desenvolvido internamente (firm specific), independentemente da difusão do conhecimento. Entretanto, situações como o descompasso tecnológico (acesso aos resultados da $\mathrm{P} \& \mathrm{D}$ de outras empresas etc.) entre as filiais de ETNs e as empresas nacionais, fazem com que os efeitos positivos do processo de aprendizado estejam, em grande medida, atrelados à difusão do conhecimento. Os efeitos de transbordamento (horizontais e verticais) têm papel destacado neste processo. Ou seja, o caráter interativo do aprendizado tem papel fundamental, dada a característica de "reação adaptativa" desenvolvida pelas ETNs e principalmente pelas empresas nacionais na indústria de transformação brasileira.

Se o conhecimento é um bem intangível, inesgotável, não deteriorável e de difícil mensuração, por sua vez o processo de aprendizado, fundamental para o avanço daquele, está relacionado a variáveis que permitem a construção de indicadores, mesmo que com limites/restrições impostas pela disponibilidade dos dados. 
Neste sentido, o nível de escolaridade dos indivíduos é uma importante variável a ser considerada para a compreensão do processo de aprendizado, mas somente na medida em que é combinada com outros fatores, como treinamento e rotina.

Para algumas funções produtivas, o treinamento é tão importante quanto o nível educacional, ainda que esse seja uma pré-condição fundamental daquele. Trata-se da importância dos trabalhadores para a trajetória da empresa; por isto a ênfase no processo de organização do trabalho, inerente à estratégia produtiva/inovativa das empresas, e na qualificação das pessoas ocupadas em atividades (neste caso em P\&D) que têm por objetivo principal a geração de inovações. Os recursos humanos são "insumos" básicos do processo de aprendizado, bem como do processo criativo.

Os gastos com treinamento complementam as informações acerca da importância do aprendizado interno nas grandes empresas nacionais e estrangeiras da indústria de transformação brasileira voltadas à inovação, ainda que os investimentos em $\mathrm{P} \& \mathrm{D}$ tenham sido restritos ao longo do período analisado. ${ }^{11}$

Começando pelas grandes empresas nacionais, observa-se que houve redução na proporção das empresas que realizaram P\&D, de 2000 para 2008 (Tabela 10), em todas as atividades econômicas consideradas. No caso das estrangeiras, a exceção a redução foi a atividade de montagem de veículos automotores, reboques e carrocerias (Tabela 11).

${ }^{11}$ O Brasil realizou investimentos totais em P\&D de US\$22,8 bilhões em 2008. A título de ilustração, a China realizou investimentos de US\$120,7 bilhões e a Coreia do Sul de US\$ 43,9 bilhões, no mesmo ano (todos os valores estão em PPC). É importante destacar que, em termos mundiais, as empresas privadas são responsáveis por cerca de dois terços dos investimentos em $\mathrm{P} \& \mathrm{D}$, ao passo que no Brasil, historicamente, estes investimentos têm sido predominantemente públicos, o que aumenta a importância do Estado na promoção de políticas de inovação. As empresas privadas foram responsáveis por $63,9 \%$ do investimento em P\&D na OCDE (em 2006), enquanto na Coreia do Sul esse percentual foi de 72,9\% (em 2008), tendo sido de 45,5\% no Brasil (em 2008) (Ministério da Ciência, Tecnologia e Inovação brasileiro (MCTI), 2014; Zucoloto, 2009; UNCTAD, 2005). 
Tabela 10 - Empresas nacionais, com 500 e mais pessoas ocupadas, que realizaram dispêndio e participação das pessoas ocupadas por nível (superior) de qualificação nas atividades internas de $P \& D$, segundo atividades selecionadas da indústria de transformação - Brasil- 2000, 2003, 2005 e 2008 (em \%)

\begin{tabular}{|c|c|c|c|c|c|c|c|c|c|c|c|c|}
\hline \multirow{2}{*}{$\begin{array}{l}\text { Indústria de } \\
\text { transformação } \\
\text { Atividade econômica }\end{array}$} & \multicolumn{4}{|c|}{$\begin{array}{l}\text { Empresas que real. P\&D } \\
\text { em relação ao total de } \\
\text { empresas }\end{array}$} & \multicolumn{4}{|c|}{$\begin{array}{c}\text { Pessoas ocupadas em P\&D em } \\
\text { relação ao total da ocupação } \\
\text { (em 31.12) }\end{array}$} & \multicolumn{4}{|c|}{$\begin{array}{l}\text { Pessoas ocupadas em P\&D, } \\
\text { com nível superior, em relação } \\
\text { ao total da ocupação em P\&D }\end{array}$} \\
\hline & 2000 & 2003 & 2005 & 2008 & 2000 & 2003 & 2005 & 2008 & 2000 & 2003 & 2005 & 2008 \\
\hline \multicolumn{13}{|c|}{ Baixa e média-baixa intensidade tecnológica } \\
\hline Alimentos e bebidas & 42,9 & 30,0 & 28,0 & 17,5 & 0,4 & 0,1 & 0,2 & 0,1 & 40,3 & 57,6 & 61,6 & 58,4 \\
\hline Produtos têxteis & 48,7 & 43,0 & 34,9 & 32,1 & 0,4 & 0,4 & 0,3 & 0,4 & 26,9 & 39,0 & 35,3 & 56,0 \\
\hline Celulose e papel & 51,6 & 50,6 & 33,3 & 29,5 & 0,6 & 0,8 & 0,6 & 0,4 & 44,7 & 57,7 & 74,9 & 61,6 \\
\hline $\begin{array}{l}\text { Artigos de borracha } \\
\text { e plásticos }\end{array}$ & 66,7 & 75,9 & 75,6 & 52,3 & 1,0 & 0,6 & 0,9 & 1,1 & 40,0 & 50,9 & 49,5 & 47,7 \\
\hline $\begin{array}{l}\text { Minerais } \\
\text { não-metálicos }\end{array}$ & 48,2 & 64,3 & 45,2 & 41,3 & 0,7 & 0,8 & 0,8 & 0,7 & 26,3 & 40,3 & 30,5 & 50,1 \\
\hline Metalurgia básica & 41,2 & 50,1 & 44,2 & 34,0 & 1,3 & 1,1 & 1,2 & 0,4 & 68,6 & 55,7 & 67,4 & 58,0 \\
\hline Produtos de metal & 62,7 & 47,0 & 43,2 & 32,7 & 0,5 & 0,7 & 0,5 & 0,5 & 45,3 & 61,1 & 39,8 & 51,7 \\
\hline $\begin{array}{l}\text { Móveis e indústrias } \\
\text { diversas }\end{array}$ & 85,7 & 69,4 & 50,0 & 37,9 & 0,1 & 1,3 & 0,7 & 0,7 & 23,7 & 44,5 & 36,5 & 44,9 \\
\hline \multicolumn{13}{|c|}{ Alta e média-alta intensidade tecnológica } \\
\hline Produtos químicos & 72,0 & 89,2 & 71,7 & 64,4 & 1,9 & 2,1 & 1,8 & 2,3 & 59,3 & 70,1 & 66,5 & 78,3 \\
\hline $\begin{array}{l}\text { Máquinas e equipa- } \\
\text { mentos }\end{array}$ & 68,9 & 60,5 & 63,6 & 49,0 & 3,1 & 2,6 & 1,7 & 1,2 & 23,0 & 35,7 & 45,0 & 47,0 \\
\hline $\begin{array}{l}\text { Máquinas, aparelhos } \\
\text { e materiais elétricos }\end{array}$ & 92,3 & 83,7 & 72,2 & 42,3 & 2,0 & 1,4 & 1,9 & 2,3 & 35,2 & 48,7 & 48,7 & 50,3 \\
\hline $\begin{array}{l}\text { Eletrônico e comuni- } \\
\text { cações }\end{array}$ & 60,0 & n.d. & n.d. & 56,6 & 1,3 & n.d. & n.d. & 2,1 & 49,7 & n.d. & n.d. & 66,5 \\
\hline $\begin{array}{l}\text { Veículos automotores, } \\
\text { reboques e carrocerias }\end{array}$ & 71,7 & 76,1 & 71,0 & 56,9 & 1,0 & 1,3 & 1,6 & 1,6 & 40,7 & 48,0 & 50,7 & 46,6 \\
\hline
\end{tabular}

Nota: n.d.= dados não disponíveis.

Fonte de dados: PINTECs 2000, 2003, 2005 e 2008 (tabulações especiais).

Em relação ao total da ocupação, verifica-se que as empresas estrangeiras (Tabela 11), em regra, apresentaram uma maior proporção de pessoas ocupadas em $\mathrm{P} \& \mathrm{D}$, se comparadas às grandes empresas nacionais da indústria de transformação brasileira. Essa situação é ainda mais destacada a favor das grandes empresas estrangeiras, quando se considera a proporção das pessoas ocupadas em $\mathrm{P} \& \mathrm{D}$, com nível superior, em relação ao total da ocupação em P\&D. 
Tabela 11 - Empresas estrangeiras, com 500 e mais pessoas ocupadas, que realizaram dispêndio e participação das pessoas ocupadas por nível (superior) de qualificação nas atividades internas de P\&D, segundo atividades selecionadas da indústria de transformação Brasil - 2000, 2003, 2005 e 2008 (em \%)

\begin{tabular}{|c|c|c|c|c|c|c|c|c|c|c|c|c|}
\hline \multirow{2}{*}{$\begin{array}{l}\text { Indústria de } \\
\text { transformação } \\
\text { Atividade econômica }\end{array}$} & \multicolumn{4}{|c|}{$\begin{array}{l}\text { Empresas que real. P\&D } \\
\text { em relação ao total de } \\
\text { empresas }\end{array}$} & \multicolumn{4}{|c|}{$\begin{array}{c}\text { Pessoas ocupadas em P\&D } \\
\text { em relação ao total da } \\
\text { ocupação (em 31.12) }\end{array}$} & \multicolumn{4}{|c|}{$\begin{array}{l}\text { Pessoas ocupadas em P\&D, } \\
\text { com nível superior, em relação } \\
\text { ao total da ocupação em P\&D }\end{array}$} \\
\hline & 2000 & 2003 & 2005 & 2008 & 2000 & 2003 & 2005 & 2008 & 2000 & 2003 & 2005 & 2008 \\
\hline \multicolumn{13}{|c|}{ Baixa e média-baixa intensidade tecnológica } \\
\hline Alimentos e bebidas & 66,8 & 57,7 & 60,5 & 55,4 & 0,4 & 0,4 & 0,6 & 0,4 & 56,3 & 68,7 & 68,7 & 69,9 \\
\hline Produtos têxteis & 42,9 & n.d. & n.d. & 40,0 & 0,4 & n.d. & n.d. & 0,4 & 18,7 & n.d. & n.d. & 78,4 \\
\hline Celulose e papel & 82,7 & n.d. & 61,3 & 70,3 & 1,0 & n.d. & 0,7 & 1,7 & 78,8 & n.d. & 59,8 & 88,9 \\
\hline $\begin{array}{l}\text { Artigos de borracha e } \\
\text { plásticos }\end{array}$ & 51,5 & n.d. & 71,4 & 42,1 & 0,5 & n.d. & 1,5 & 1,2 & 59,4 & n.d. & 61,0 & 67,1 \\
\hline $\begin{array}{l}\text { Minerais } \\
\text { não-metálicos }\end{array}$ & 60,0 & n.d. & 50,0 & 50,0 & 0,5 & n.d. & 0,6 & 0,4 & 67,2 & n.d. & 67,2 & 45,7 \\
\hline Metalurgia básica & 60,0 & 64,9 & 84,6 & 52,4 & 0,3 & 1,5 & 1,0 & 1,9 & 56,4 & 69,1 & 51,3 & 58,8 \\
\hline Produtos de metal & 66,2 & n.d. & n.d. & 41,7 & 0,1 & n.d. & n.d. & 0,4 & 34,9 & n.d. & n.d. & 79,9 \\
\hline $\begin{array}{l}\text { Móveis e indústrias } \\
\text { diversas }\end{array}$ & 85,7 & n.d. & n.d. & 80,0 & 0,1 & n.d. & n.d. & 0,5 & 31,3 & n.d. & n.d. & 72,7 \\
\hline \multicolumn{13}{|c|}{ Alta e média-alta intensidade tecnológica } \\
\hline Produtos químicos & 73,9 & 74,8 & 64,2 & 64,7 & 2,0 & 1,6 & 2,1 & 1,5 & 62,6 & 69,3 & 67,0 & 81,0 \\
\hline $\begin{array}{l}\text { Máquinas e } \\
\text { equipamentos }\end{array}$ & 73,8 & 79,7 & 61,9 & 50,0 & 1,8 & 1,7 & 1,2 & 0,9 & 54,6 & 61,5 & 68,8 & 72,1 \\
\hline $\begin{array}{l}\text { Máquinas, aparelhos e } \\
\text { materiais elétricos }\end{array}$ & 69,5 & 57,9 & 69,2 & 46,7 & 2,3 & 0,9 & 2,6 & 1,8 & 73,5 & 89,3 & 61,6 & 78,1 \\
\hline $\begin{array}{l}\text { Eletrônico e } \\
\text { comunicações }\end{array}$ & 65,5 & 74,6 & 64,3 & 50,4 & 5,5 & 4,3 & 3,4 & 2,5 & 67,1 & 81,0 & 90,9 & 89,3 \\
\hline $\begin{array}{l}\text { Veículos automotores, } \\
\text { reboques e carrocerias }\end{array}$ & 66,5 & 77,2 & 70,5 & 70,1 & 1,9 & 2,7 & 2,6 & 3,1 & 60,9 & 70,3 & 50,7 & 68,9 \\
\hline
\end{tabular}

Nota: n.d. = dados não disponíveis.

Fonte de dados: PINTECs 2000, 2003, 2005 e 2008 (tabulações especiais).

Em suma, quanto maior a intensidade tecnológica da produção, maior tem sido a proporção de pessoas ocupadas em $P \& D$ e com maior nível educacional. Essa condição é válida para as grandes empresas nacionais e, sobretudo, para as estrangeiras, sendo compatível com as exigências de se promover/absorver inovações com maior velocidade em atividades tecnologicamente mais dinâmicas, principalmente no que se refere à necessidade de atuação em diferentes mercados, no caso das grandes empresas estrangeiras. 
Por sua vez, os dispêndios em "atividade interna de P\&D", em relação a sua receita líquida de vendas (RLV) (esforço inovativo) (Tabelas 12 e 13), têm sido mais elevados nas atividades de maior intensidade tecnológica, tanto entre as grandes empresas estrangeiras como entre as nacionais. Neste caso, também as empresas estrangeiras têm apresentado, em regra, uma proporção de gastos em relação ao total dos dispêndios superior às empresas nacionais.

Tabela 12 - Dispêndio em atividades inovativas selecionadas, como percentual da receita líquida de vendas das empresas nacionais com 500 e mais pessoas ocupadas, por atividades selecionadas da indústria de transformação - Brasil- 2000, 2003 e 2008

\begin{tabular}{|c|c|c|c|c|c|c|c|c|c|c|c|c|c|c|c|c|}
\hline \multirow{2}{*}{$\begin{array}{l}\text { Indústria de } \\
\text { transformação } \\
\text { Atividade econômica }\end{array}$} & \multicolumn{4}{|c|}{ Atividade Interna de P\&D } & \multicolumn{4}{|c|}{$\begin{array}{c}\text { Aquisição máquinas } \\
\text { e equipamentos }\end{array}$} & \multicolumn{4}{|c|}{ Treinamento } & \multicolumn{4}{|c|}{$\begin{array}{l}\text { Introdução de Inovações } \\
\text { Tecnológicas no mercado }\end{array}$} \\
\hline & 2000 & 2003 & 2005 & 2008 & 2000 & 2003 & 2005 & 2008 & 2000 & 2003 & 2005 & 2008 & 2000 & 2003 & 2005 & 2008 \\
\hline \multicolumn{17}{|c|}{ Baixa e média-baixa intensidade tecnológica } \\
\hline Alimentos e bebidas & 0,30 & 0,07 & 0,07 & 0,08 & 1,14 & 0,82 & 1,11 & 1,29 & 0,04 & 0,02 & 0,03 & 0,02 & 0,12 & 0,15 & 0,09 & 0,06 \\
\hline Produtos têxteis & 0,32 & 0,23 & 0,31 & 0,30 & 2,93 & 2,62 & 0,63 & 1,95 & 0,07 & 0,04 & 0,05 & 0,13 & 0,12 & 0,07 & 0,14 & 0,07 \\
\hline Celulose e papel & 0,30 & 0,31 & 0,33 & 0,31 & 3,27 & 1,99 & 2,10 & 1,08 & 0,08 & 0,03 & 0,02 & 0,05 & 0,12 & 0,02 & 0,07 & 0,03 \\
\hline $\begin{array}{l}\text { Artigos de borracha e } \\
\text { plásticos }\end{array}$ & 0,52 & 0,35 & 0,38 & 0,43 & 1,87 & 0,62 & 1,43 & 1,03 & 0,05 & 0,04 & 0,04 & 0,04 & 0,07 & 0,10 & 0,11 & 0,16 \\
\hline Minerais não-metálicos & 0,40 & 0,29 & 0,48 & 0,35 & 2,48 & 1,18 & 0,59 & 1,97 & 0,08 & 0,05 & 0,04 & 0,02 & 0,06 & 0,09 & 0,07 & 0,08 \\
\hline Metalurgia básica & 0,54 & 0,28 & 0,20 & 0,18 & 7,66 & 0,90 & 1,10 & 1,90 & 0,08 & 0,03 & 0,04 & 0,15 & 0,02 & 0,02 & 0,03 & 0,01 \\
\hline Produtos de metal & 0,52 & 0,56 & 0,34 & 0,67 & 2,58 & 0,69 & 1,41 & 0,94 & 0,17 & 0,02 & 0,06 & 0,13 & 1,01 & 0,16 & 0,05 & 0,11 \\
\hline $\begin{array}{l}\text { Móveis e indústrias } \\
\text { diversas }\end{array}$ & 0,58 & 0,77 & 1,05 & 0,71 & 1,40 & 2,16 & 1,06 & 0,43 & 0,14 & 0,09 & 0,06 & 0,04 & 1,11 & 0,71 & 1,07 & 0,15 \\
\hline \multicolumn{17}{|c|}{ Alta e média-alta intensidade tecnológica } \\
\hline Produtos químicos & 0,55 & 0,49 & 0,56 & 0,80 & 0,80 & 0,68 & 0,58 & 1,79 & 0,03 & 0,03 & 0,02 & 0,05 & 0,33 & 0,35 & 0,27 & 0,34 \\
\hline $\begin{array}{l}\text { Máquinas e } \\
\text { equipamentos }\end{array}$ & 1,40 & 1,41 & 1,13 & 0,70 & 1,59 & 4,30 & 2,29 & 1,14 & 0,27 & 0,08 & 0,11 & 0,05 & 0,39 & 0,27 & 0,44 & 0,06 \\
\hline $\begin{array}{l}\text { Máquinas, aparelhos } \\
\text { e materiais elétricos }\end{array}$ & 1,79 & 0,82 & 1,96 & 0,91 & 3,57 & 0,81 & 0,48 & 0,76 & 0,10 & 0,03 & 0,09 & 0,02 & 0,16 & 0,03 & 0,02 & 0,24 \\
\hline $\begin{array}{l}\text { Eletrônico e } \\
\text { comunicações }\end{array}$ & 0,47 & n.d. & n.d. & 0,59 & 0,39 & n.d. & n.d. & 0,14 & 0,03 & n.d. & n.d. & 0,01 & 0,08 & n.d. & n.d. & 1,84 \\
\hline $\begin{array}{l}\text { Veículos automotores, } \\
\text { reboques e carrocerias }\end{array}$ & 0,88 & 0,82 & 0,75 & 1,19 & 1,21 & 1,12 & 0,95 & 1,84 & 0,11 & 0,07 & 0,06 & 0,07 & 0,14 & 0,14 & 1,31 & 0,32 \\
\hline
\end{tabular}

Nota: n.d. = dados não disponíveis.

Fonte de dados: PINTECs 2000, 2003, 2005 e 2008 (tabulações especiais).

Destaca-se o esforço inovativo, tanto para as grandes empresas nacionais como para as estrangeiras, na "aquisição de máquinas e equipamentos", como forma de atualização tecnológica da estrutura produtiva das empresas, inclusive superando, na maior parte das atividades no período considerado, o esforço em "atividade interna de P\&D". 
Tabela 13 - Dispêndio em atividades inovativas selecionadas, como percentual da receita líquida de vendas das empresas estrangeiras com 500 e mais pessoas ocupadas, por atividades selecionadas da indústria de transformação - Brasil- 2000, 2003, 2005 e 2008

\begin{tabular}{|c|c|c|c|c|c|c|c|c|c|c|c|c|c|c|c|c|}
\hline \multirow{2}{*}{$\begin{array}{l}\text { Indústria de } \\
\text { transformação } \\
\text { Atividade econômica }\end{array}$} & \multicolumn{4}{|c|}{$\begin{array}{c}\text { Atividade Interna } \\
\text { de P\&D }\end{array}$} & \multicolumn{4}{|c|}{$\begin{array}{c}\text { Aquisição máquinas } \\
\text { e equipamentos }\end{array}$} & \multicolumn{4}{|c|}{ Treinamento } & \multicolumn{4}{|c|}{$\begin{array}{l}\text { Introdução de Inovações } \\
\text { Tecnológicas no mercado }\end{array}$} \\
\hline & 2000 & 2003 & 2005 & 2008 & 2000 & 2003 & 2005 & 2008 & 2000 & 2003 & 2005 & 2008 & 2000 & 2003 & 2005 & 2008 \\
\hline \multicolumn{17}{|c|}{ Baixa e média-baixa intensidade tecnológica } \\
\hline Alimentos e bebidas & 0,20 & 0,23 & 0,15 & 0,58 & 1,03 & 1,76 & 0,69 & 1,74 & 0,02 & 0,03 & 0,01 & 0,03 & 0,98 & 0,44 & 0,16 & 0,18 \\
\hline Produtos têxteis & 0,20 & n.d. & n.d. & 0,25 & 0,65 & n.d. & n.d. & 0,37 & 0,02 & n.d. & n.d. & 0,02 & 0,05 & n.d. & n.d. & 0,06 \\
\hline Celulose e papel & 0,47 & n.d. & 0,26 & 0,72 & 2,55 & n.d. & 1,51 & 0,76 & 0,02 & n.d. & 0,05 & 0,05 & 0,28 & n.d. & 0,84 & 0,19 \\
\hline $\begin{array}{l}\text { Artigos de borracha } \\
\text { e plásticos }\end{array}$ & 0,65 & n.d. & 0,65 & 1,55 & 2,26 & n.d. & 0,45 & 0,44 & 0,03 & n.d. & 0,05 & 0,12 & 0,01 & n.d. & 0,03 & 0,13 \\
\hline $\begin{array}{l}\text { Minerais } \\
\text { não-metálicos }\end{array}$ & 26 & n.d. & 46 & 4 & 1,85 & n.d. & 09 & 1,16 & 03 & n.d. & 0,07 & 0,01 & n.d. & n.d. & 0,35 & 0,01 \\
\hline Metalurgia básica & 0,22 & 0,30 & 0,29 & 0,30 & 1,10 & 1,28 & 2,50 & 2,65 & 0,01 & 0,09 & 0,01 & 0,04 & 0,07 & 0,06 & 0,08 & 0,01 \\
\hline Produtos de metal & 0,02 & n.d. & n.d. & 0,10 & 0,61 & n.d. & n.d. & 1,07 & n.d. & $n$ & t. & 0,01 & n.d. & n.d. & n.d. & 0,02 \\
\hline $\begin{array}{l}\text { Móveis e indústrias } \\
\text { diversas }\end{array}$ & 0,24 & n.d. & n.d. & 0,57 & 1,36 & n.d. & n.d. & 2,71 & 0,03 & n.d. & n.d. & 0,14 & 0,02 & n.d. & n.d. & 0,36 \\
\hline \multicolumn{17}{|c|}{ Alta e média-alta intensidade tecnológica } \\
\hline rodutos químicos & 0,87 & 0,52 & 0,51 & 1,01 & 1,19 & 0,97 & 1,06 & 0,77 & 0,10 & 0,04 & 0,04 & 0,01 & 0,63 & 0,18 & 0,44 & 0,30 \\
\hline Máquinas e & 1,01 & 0,49 & 0,41 & 0,66 & 2,18 & 1,34 & 0,57 & 0,74 & 0,08 & 0,06 & 0,03 & 0,07 & 0,29 & 0,10 & 0,08 & 0,02 \\
\hline $\begin{array}{l}\text { Máquinas, aparelhos } \\
\text { e materiais elétricos }\end{array}$ & 2,38 & 0,55 & 2,01 & 1,74 & 2,53 & 1,87 & 0,75 & 0,86 & 0,24 & 0,06 & 0,03 & 0,08 & 0,16 & 0,09 & 0,06 & 0,21 \\
\hline $\begin{array}{l}\text { Eletrônico e } \\
\text { comunicações }\end{array}$ & 2,14 & 1,22 & 0,64 & 1,19 & 1,87 & 1,87 & 0,57 & 0,19 & 0,10 & 0,03 & 0,05 & 0,02 & 0,17 & 0,65 & 0,61 & 0,62 \\
\hline $\begin{array}{l}\text { Veículos automotores, } \\
\text { reboques e carrocerias }\end{array}$ & 1,02 & 1,89 & 1,51 & 1,84 & 2,43 & 1,98 & 2,01 & 0,59 & 0,05 & 0,05 & 0,08 & 0,02 & 0,94 & 0,13 & 0,23 & 0,16 \\
\hline
\end{tabular}

Nota: n.d.= dados não disponíveis.

Fonte de dados: PINTECs 2000, 2003, 2005 e 2008 (tabulações especiais).

Em relação ao esforço inovativo com treinamento (gastos com treinamento em relação à RLV), observa-se que, tanto para as grandes empresas nacionais como para as estrangeiras, os gastos, além de reduzidos, para a maior parte das atividades inovativas empreendidas em 2000, 2003, 2005 e 2008 se encontravam em queda na maior parte das atividades analisadas.

Em linhas gerais, considerando-se em conjunto, a qualificação das pessoas ocupadas e os esforços inovativos com $\mathrm{P} \& \mathrm{D}$, conforme os dados referentes aos anos de 2000, 2003, 2005 e 2008, houve uma tendência à redução da importância da geração de inovações, via investimentos relacionados à $\mathrm{P} \& \mathrm{D}$, a partir das grandes empresas da indústria de transformação brasileira. Nesse sentido, observa-se que a situação das grandes empresas nacionais foi ainda mais desfavorável, quando comparadas às estrangeiras. 
Somente no caso das grandes empresas estrangeiras, na fabricação e montagem de veículos automotores, reboques e carrocerias, houve uma combinação positiva entre o crescimento dos esforços inovativos em $\mathrm{P} \& \mathrm{D}$, acompanhados de aumento na qualificação do pessoal ocupado, no período considerado, apresentando um quadro favorável ao desenvolvimento de atividades inovativas.

\section{Considerações finais}

Quanto maiores são as empresas, maiores tendem a ser os efeitos dos seus processos inovativos sobre os demais agentes da inovação. No entanto, na medida em que as grandes empresas estrangeiras internalizam (intra-corporação) grande parte de seus processos inovativos acabam limitando a sua influência sobre os efeitos de transbordamento, como tem ocorrido no Brasil.

As relações de cooperação não têm indicada uma participação favorável ao desenvolvimento de "parcerias" inovativas, entre concorrentes e dentro das cadeias produtivas, por parte das empresas estrangeiras, quando comparadas às nacionais. Especificamente no que se refere ao "esforço inovativo" empreendido pelas grandes empresas estrangeiras da indústria de transformação brasileira, a contribuição destas empresas tem sido pouco expressiva para a promoção de atividades inovativas a partir da economia brasileira. Depreende-se desta situação que estes processos têm sido desenvolvidos em outras economias, dada a limitada necessidade do uso de estratégias corporativas para a promoção de inovações por parte das ETNs em território brasileiro. A estratégia de fornecimento global, associada à de busca de mercado, por parte das ETNs, acaba limitando o acesso das empresas locais ao processo de desverticalização e, por conseguinte, reduzindo os efeitos positivos dos transbordamentos do conhecimento (horizontais e verticais), dado que o processo de aprendizado continua internalizado nas filiais de ETNs e seus fornecedores internacionais, quando se avalia sob a ótica das organizações nacionais com potencial inovativo (os "parceiros"). 
Os indicadores demonstram que, no caso das grandes empresas estrangeiras, as estratégias intra-corporativas têm se apresentado como a principal alternativa para promoção de atividades inovativas. $\mathrm{Ou}$ seja, a cooperação, como forma de difusão do conhecimento, tem estado condicionada pela "hierarquia organizacional" que controla a realização de inovações, o que tem limitado os efeitos de transbordamento na economia nacional, à medida que esta tem disputado IEDs com outras economias que têm apresentado melhores condições em termos de infra-estrutura tecnológica e SIs.

Se, por um lado, a abertura econômica e a reestruturação produtiva permitiram uma maior facilidade de acesso (externo) a bens de capital e ativos complementares por parte das ETNs instaladas no Brasil, o que acabou por facilitar a atualização tecnológica via comércio intra-firma etc., por outro, afetaram negativamente as possibilidades de indução da pesquisa no desenvolvimento de produtos e processos em "parceria" com outras organizações nacionais. Evidência disso é que os principais "parceiros" das grandes empresas estrangeiras seguem sendo as empresas do "grupo", e o exterior continua sendo a localização fundamental das "fontes de informação" associadas à inovação.

No caso da indústria de transformação brasileira, apesar da trajetória histórica das filiais de ETNs, que demonstra o seu elevado nível de "enraizamento" na economia nacional, os indicadores sobre "fontes de informação" e "parceria" para a inovação, sinalizam para uma fraca interação entre aquelas empresas e os demais agentes da inovação em território nacional. A atuação "em rede", como inovação organizacional fundamental do atual paradigma tecno-econômico, combinou a desverticalização com o aprofundamento das relações intra-corporativas, ao invés de estimular a difusão do conhecimento, conforme revelam os indicadores sobre "cooperação". Neste sentido, do ponto de vista das organizações/instituições nacionais, as ETNs caracterizaram-se mais como "empresas em rede" do que como "rede de empresas", demonstrando os limites da sua atuação em relação à necessidade de difusão de inovações organizacionais compatíveis com o atual paradigma tecno-econômico, ou seja, confirmando as suas escassas relações de "parceria" com outras organizações nacionais para a promoção de processos inovativos a partir da economia nacional. 
A reduzida cooperação em $\mathrm{P} \& \mathrm{D}$ entre as grandes empresas estrangeiras e outras organizações nacionais, se comparada a outras formas de cooperação, por sua vez, revela uma necessidade de transformações organizacionais que não estão balizadas por atividades inovativas, contribuindo para retardar o desenvolvimento competitivo (tecnológico e organizacional) da economia nacional, em função do elevado grau de desnacionalização da sua estrutura produtiva industrial.

Em suma, as restrições às interações de natureza inovativa, no caso brasileiro, são, assim, entendidas como um indicador do limite da influência das grandes empresas estrangeiras sobre o avanço tecnológico, organizacional e institucional de seu ambiente de interação, ou seja, sinalizam em relação aos impactos, pouco favoráveis, do comportamento inovativo destas empresas para o desenvolvimento do SNI do País.

\section{Referências}

ARAÚJO, R. D. de. Esforços tecnológicos das firmas transnacionais e domésticas. In: DE NEGRI, J. A.; SALERNO, M. S. (Orgs.). Inovações, padrões tecnológicos e desempenho das firmas industriais brasileiras. Brasília: IPEA. Cap. 14, p. 119-170, 2005.

BANCO CENTRAL DO BRASIL (BCB). Censo de Capitais Estrangeiros. 1995, 2000 e 2005. Disponível em: <http://www.bcb.gov.br/?CENSOCE>. Acesso em: setembro de 2010.

CARLEIAL, L. Redes industriais de subcontratação: um enfoque de sistema nacional de inovação. São Paulo: HUCITEC, 2001.

CASTRO, A.B. de. Brazil's second catch-up: characteristics and constraints. Cepal Review, n. 80, p. 71-80, aug. 2003.

CENTRO DE GESTÃO E ESTUDOS ESTRATÉGICOS-CGEE/ASSOCIAÇÃO NACIONAL DE PESQUISA E DESENVOLVIMENTO DAS EMPRESAS INOVADORAS-ANPEI. Os novos instrumentos de apoio à inovação: uma avaliação inicial. Brasília-DF: 2009.

CIMOLI, M.; DOSI, G.; NELSON, R. R.; STIGLITZ, J. Instituições e políticas moldando o desenvolvimento industrial: uma nota introdutória. Revista Brasileira de Inovação, v. 6, n. 1, p. 55-85, jan./jun. 2007.

COMISSÃO ECONÔMICA PARA A AMÉRICA LATINA E CARIBE (CEPAL). Investimento estrangeiro na América Latina e no Caribe. Documento Informativo, 2004.

CORIAT, B. (1991). Pensar pelo avesso: o modelo japonês de trabalho e organização. Rio de Janeiro: Revan: UFRJ, 1994.

DE NEGRI, F. Investimento direto e transferência de tecnologia: Argentina, Brasil e México. Campinas-SP: Instituto de Economia-UNICAMP (Tese de doutorado), 2007.

DE NEGRI, J. A.; SALERNO, M. S. (Orgs.). Inovações, padrões tecnológicos e desempenho das firmas industriais brasileiras. Brasília: IPEA, 2005. 
EDQUIST, C. The systems of innovation approach and innovation policy: an account of the state of the art. DRUID Conference, Aalborg University, June 12-15, 2001.

ERNST, H. Global production networks and the changing geography of innovation system: implications for developing countries. East-west Center Working Papers - Economics Series, n. 9, nov. 2000.

FREEMAN, C. The 'National System of Innovation' in historical perspective. Cambridge Journal of Economics, v. 19, p. 5-24, 1995.

INSTITUTO BRASILEIRO DE GEOGRAFIA E ESTATÍSTICA (IBGE). Pesquisa de Inovação Tecnológica - 2005. Rio de Janeiro: IBGE, 2007.

JOHNSON, B.; LUNDVALL, B-Â. Promovendo sistemas de inovação como resposta à economia do aprendizado crescentemente globalizada. In: LASTRES, H. M. M.; CASSIOLATO, J. E.; ARROIO, A. (Orgs.). Conhecimento, sistemas de inovação e desenvolvimento. (Tradução Ana Arroio). Rio de Janeiro: Editora UFRJ- Contraponto. p. 83-130, 2005.

KATZ, J. Reformas estruturais orientadas para o mercado, globalização e transformação dos sistemas de inovação latino-americanos. In: CASTRO, A. C. et al (Org.). Brasil em desenvolvimento 1: economia, tecnologia e competitividade. Rio de Janeiro: Civilização Brasileira. p. 351-384, 2005.

LAPLANE, M. F.; SARTI, F. Investimento direto estrangeiro no Brasil nos anos 90: determinantes e estratégias. In: CHUDNOVSKY, D. (Org.). Investimentos externos no Mercosul. Campinas/SP: Papirus: IE- Unicamp, p. 197-300, 1999.

LUNDVAL, B-Â. The social dimension of the learning economy. DRUID Working Papers, n. 96-1, April 1996.

LUNDVALL, B-Â. National Innovation System: analytical Focusing Device and Policy Learning Tool. Swedish Institute for Growth Policy Studies- ITPS. Working Paper 4, 2007.

MINISTÉRIO DA CIÊNCIA, TECNOLOGIA E INOVAÇÃO (MCTI). Disponível em: < http://www. mcti.gov.br/index.php/content/view/2076.html>. Acesso em: 27/02/2014.

NELSON, R. R. (1996). As fontes do crescimento econômico. Campinas/SP: Editora da Unicamp, 2006. Bringing institutions into evolutionary growth theory. Journal of Evolutionary Economics, n. 12, p. 17-28, 2002.

. Economic Development from the perspective of evolutionary economic theory. Working Papers in Technology, Governance and Economic Dynamics, n. 2, 2006. Disponível em: <http://tg.deca. ee/files/main/2006013112494141.pdf>. Acesso em: 15 de agosto de 2008.

PÉREZ, C. Cambio tecnológico y oportunidades de desarrollo como blanco móvil. Revista de La CEPAL, n. 75, p. 115-136, Diciembre 2001

RODRÍGUEZ, O. La agenda del desarrollo (elementos para su discusión). Economia-Ensaios, n. 16(2)/17(1), jul./dez. 2002.

RUIZ, A. U. Patrones de inserción de las empresas multinacionales en la formación de competencias tecnológicas de países seguidores. Revista Brasileira de Inovação, v.6, n.2, p.405-432, jul./dez. 2007.

SARTI, F.; LAPLANE, M. O investimento direto estrangeiro e a internacionalização da economia brasileira nos anos 1990. Economia e Sociedade, v. 11, n. 1 (18), p. 63-94, jan./jun. de 2002.

UNITED NATIONS CONFERENCE ON TRADE AND DEVELOPMENT (UNCTAD). Transnational corporations and the internationalization of R\&D. World Investment Report (WIR), 2005.

WILLIAMSON, O. E. Las instituciones económicas del capitalismo. México: FCE, 1989.

ZUCOLOTO, G. F. Desenvolvimento tecnológico por origem de capital no Brasil: P\&D, patentes e incentivos públicos. Rio de Janeiro: Instituto de Economia-UFRJ, 2009. (Tese de doutorado). 